\title{
A Model of Intertemporal Asset Prices Under Asymmetric Information
}

\author{
JIANG WANG \\ Massachusetts Institute of Technology
}

First version received February 1991, final version accepted September 1992 (Eds.)

\begin{abstract}
This paper presents a dynamic asset-pricing model under asymmetric information. Investors have different information concerning the future growth rate of dividends. They rationally extract information from prices as well as dividends and maximize their expected utility. The model has a closed-form solution to the rational expectations equilibrium. We find that existence of uninformed investors increases the risk premium. Supply shocks can affect the risk premium only under asymmetric information. Information asymmetry among investors can increase price volatility and negative autocorrelation in returns. Less-informed investors may rationally behave like price chasers.
\end{abstract}

\section{INTRODUCTION}

In this paper, we present a model of dynamic asset pricing under asymmetric information. We consider an economy endowed with a given quantity of equity. The dividends on the equity grow at a stochastic rate. The investors in the economy can be either informed or uninformed: the informed investors know the future dividend growth rate, while the uninformed investors do not. All the investors observe current dividend payments and stock prices. Since the growth rate of dividends determines the rate of appreciation of stock prices, changes of prices provide signals about the future growth of dividends. Uninformed investors rationally extract information about the state of the economy from prices as well as dividends. Since we assume an incomplete market structure, the signals do not fully reveal the true values of all the state variables. In equilibrium. investors with access to different information will anticipate different expected returns from investing in stocks.

We explore the implications of our model for the behaviour of stock prices, price volatility, risk premia, serial correlation in stock returns and investors' trading strategies.

One application of our model is to examine the relation between the information structure of the market and price variability. Several authors have argued that a typical asset pricing model with identical investors cannot reconcile the large volatility of stock prices observed in the market with the history of smooth dividends. ${ }^{1}$ Campbell and Kyle (1988) suggest that the existence of noise trading in the market can help explain the high volatility of stock prices. ${ }^{2}$ Using our model, we show that the imperfect information of some investors can cause stock prices to be more volatile than in the case where all investors are perfectly informed. Two factors contribute to price volatility: changing

1. See LeRoy and Porter (1981) and Shiller (1981). See also Flavin (1983), Kleidon (1986), Marsh and Merton (1986), Mankiw, Romer and Shapiro (1985), Campbell and Shiller (1988) and West (1988).

2. In this paper, we use the terminology "supply shocks" instead of "noise trading". 
expectations about future cash flows and noise trading. When investors are less informed about the true growth rate of dividends, their expectation about future cash flows becomes less variable. This has the effect of reducing price volatility. On the other hand, there is more uncertainty in the stock's future cash flows. Investors demand higher premium in accommodating the noise trading and prices become more sensitive to supply shocks. This has the effect of increasing price volatility. The net change in price volatility depends on which of the two effects dominates. When noise trading is important, prices become more volatile as investors become less informed.

Furthermore, we find that information asymmetry among investors can cause price volatility to increase. Under information asymmetry, more-informed investors trade on superior information against less informed investors. Hence, less-informed investors face an adverse selection problem when they respond to noise trading. They demand additional premium for the risk of trading against better informed investors. This results in increasing price elasticity to supply shocks and price volatility.

Another application of our model revolves around the understanding of equity premia. We show that the existence of uninformed investors can lead to risk premia much higher than that under symmetric and perfect information. When more investors are less informed, prices contain less information about the fundamentals of the stocks. There is more uncertainty in the stocks' future cash flows (for the less-informed investors). Higher premia are required by the less informed investors to invest in stocks. Hence, as the fraction of uninformed investors in the economy increases the risk premia on stocks also increase. ${ }^{3}$

De Long et al. (1990) have suggested that noise trading in the market can increase price volatility, hence the risk of investing in the stock market and the risk premia. The key assumption that leads to their result is that some investors have finite investment horizons. The current model assumes an infinite horizon for all investors. It is shown that the unconditional expected excess returns on the stocks only depend on the risk in the stocks' future cash flows (the stocks' "fundamental risk"). Even though noise trading does move prices and increase price volatility, without information asymmetry it does not affect the risk premia since it does not change stocks' fundamental risk. However, when there is information asymmetry in the market, noise trading will affect the information quality of prices in revealing private information about the stocks' future cash flows. More noise trading makes prices less informative about future dividend growth. This increases the uncertainty of future cash flows to the less informed investors, hence the required return. Therefore, in our model noise trading affect risk premia only under information asymmetry.

Recent empirical studies suggest that there may exist significant negative serial correlation in long-horizon stock returns. ${ }^{4}$ Due to mean reversion in the underlying state variables that affect the expected excess returns, stock returns can be negatively serially correlated. However, when information asymmetry is present, the less-informed investors can only learn about these state variables from realized returns. This increases the dependence of their expected future returns on past returns and may enhance the negative serial correlation in stock returns.

We also apply our model to analyze the trading strategies of investors with different information sets. When information asymmetry is present, the informed investors' stock

3. We do not explore the implications of information asymmetry on the connection between aggregate consumption and risk premia (see, for example, Grossman and Shiller (1981) and Mehra and Prescott (1985)). A discussion along this line would be more directly related to the Mehra-Prescott "equity premium puzzle".

4. See Fama and French (1987), Lo and MacKinlay (1988) and Poterba and Summers (1988). 
holdings not only depend on the value of underlying state variables but also depend on the reaction of uninformed investors. Informed investors take advantage of the errors made by less-informed investors to make profits. The uninformed investors trade based on information extracted from prices and dividends. We find that in some cases, the uninformed investors rationally adopt trading strategies that look like trend chasing: they buy stocks when prices go up and sell when prices go down. A number of studies present evidence consistent with this type of trend-chasing strategy. ${ }^{5}$ Our results show that trend-chasing-like behaviour can be rational for less-informed investors under asymmetric information while informed investors behave as contrarians.

There are two major obstacles in tackling the problem of dynamic asset pricing under asymmetric information. One is the notion of "no trading" and/or "fully revealing" (Grossman (1981), and Milgrom and Stokey (1985)) and the other is the mathematical difficulty involved in deriving the equilibrium. The "no-trading theorem" states that if asymmetric information is the only motivation for trading, then an investor reveals his information to the market by his willingness to trade. Hence, information asymmetry is eliminated in equilibrium and no trade actually occurs as new information comes in. This result crucially depends on the market structure of the economy (see, e.g., Grossman $(1977,1981))$. Under incomplete markets, there can be motivations other than the arrival of new information that cause investors to trade. In this case, the argument for the irrelevance of heterogeneous information breaks down. When information asymmetry is coupled with an incomplete market structure, the problem becomes mathematically involved. $^{6}$ The current model, to our knowledge, is the first dynamic asset pricing model under asymmetric information which provides a closed-form solution. ${ }^{7}$

We organize the paper as follows. The formal model is spelled out in Section 2. In Section 3, we consider the simple situation in which investors have homogeneous and perfect information about the economy. This provides a benchmark case for our economy. A rational expectations equilibrium of the full model is obtained in Section 4 by sequentially solving the problems of investors' rational learning, optimization and market equilibrium. In Section 5, we investigate how the underlying information structure of the economy, especially information asymmetry, affects risk premia, price volatility and serial correlation in returns. In Section 6, we analyze the optimal investment strategies of investors with different information. Some further comments are provided in Section 7. Section 8 concludes.

\section{THE ECONOMY}

We consider a simple economy with a single physical good. The economy is defined as follows.

Assumption 1. The economy is endowed with a certain amount of risky equity. Each unit of the risky equity generates a flow of output (dividend) at an instantaneous

5. See, Anderassen and Kraus (1988), Case and Shiller (1988), Frenkel and Froot (1988) and Shiller (1987). See also Soros (1987).

6. See Duffie and Huang (1986) and He and Pearson (1988).

7. The information structure in this paper is similar to the one considered by Townsend (1981). Singleton (1985), Carino (1986) considered models in which all private information becomes public after a short period (one or two periods) so that effectively the less-informed investors' learning problem becomes a static one. In this paper, we allow private information to remain private. Therefore, the less-informed investors' learning problem becomes dynamic which generates interesting results concerning their optimal investment strategies and equilibrium prices. 
rate $D . D$ is governed by the diffusion process:

$$
d D=(\Pi-k D) d t+b_{D} d \underline{w},
$$

where $\Pi$ is a state variable following an Ornstein-Uhlenbeck $(\mathrm{O}-\mathrm{U})$ process

$$
d \Pi=a_{\Pi}(\bar{\Pi}-\Pi) d t+b_{\Pi} d \underline{w} .
$$

$\underline{w}$ is a $(3 \times 1)$ vector of independent standard Wiener processes, $a_{\Pi}(>0), \bar{\Pi}, k(\geqq 0)$ are constants, and $b_{D}, b_{\Pi}$ are $(1 \times 3)$ constant matrices. $^{8}$

Clearly, $(\Pi-k D)$ gives the expected growth rate of dividends. When $k>0, \Pi / k$ can be interpreted as the short-run steady-state level of the dividend rate $D$, and it fluctuates around a long-run steady-state level $\bar{\Pi} / k$. When $k=0, \Pi$ is simply the dividend growth rate. Hence, when $k>0$ and $a_{\Pi}>0$ the dividend (and price) is stationary around a fixed mean while when $k=0$, the dividend (and price) becomes non-stationary. $\boldsymbol{b}_{D} d \underline{w}$ and $b_{\Pi} d \underline{w}$ respectively give the innovations in $D$ and $\Pi .(D, \Pi)$ is a Gaussian Markov system.

Assumption 2. Let the total amount of risky equity be $1+\Theta$. $\Theta$ satisfies the stochastic differential equation:

$$
d \Theta=-a_{\Theta} \Theta d t+\boldsymbol{b}_{\Theta} d \underline{w},
$$

where $a_{\Theta}$ is a positive constant and $\boldsymbol{b}_{\Theta}$ is a $(1 \times 3)$ constant matrix. $^{9}$

By Assumption 2, the total supply of the risky capital is stochastic. It has a long-run stationary level which is normalized to 1 . $\Theta$ gives the deviation of the current supply from its long-run stationary level.

Assumption 3. Each unit of the risky capital is represented by one perfectly divisible share of stock held by the investors in the economy. Shares are traded in a competitive stock market with no transactions costs. The stock is the only security that is traded in the market. Let $P$ be the equilibrium price of the stock. ${ }^{10}$

Assumption 4. There is a risk-free storage technology available to the economy with a constant rate of return $1+r(r>0)$. All investors have access to the storage technology at no cost. ${ }^{11}$

In order to have incomplete markets, we have introduced an additional state variable by assuming the aggregate quantity of the risky capital to be stochastic. This is only for simplicity in exposition. The incompleteness of the market can be modelled in a rational, self-contained framework without making ad hoc assumptions about the stock supply or investors' behaviour. In particular, Wang (1990) has generated the same result by assuming

8. With this form of the dividend process, $D$ can take negative values. However, one can make the probability of $D$ reaching negative values as small as any given positive number by choosing the parameter values (see, for example, Campbell and Kyle (1988)). One interpretation for negative dividends is that investors have to put back some investments to maintain the future cash flow.

9. An equivalent interpretation to the stochastic supply is the existence of noise traders with their demand of the stock being $-\Theta$.

10. We do not allow free disposal of the stock. Therefore, the shares in this model do not have the property of limited liability. Hence, it is possible for the price of the stock to take negative values since the stock's future cash flow can be negative.

11. A general equilibrium justification for a constant interest rate in an economy with CARA preferences is given by Sundaresan (1983). 
rational investors, fixed stock supply and possibilities of risky production. Furthermore, we have restricted the stock to be the only security traded in the market. ${ }^{12}$

Assumption 5. There are two types of investors in the economy: the informed and the uninformed. $\mathscr{F}^{\mathrm{i}}(t)=\left\{D_{\tau}, P_{\tau}, \Pi_{\tau}: \tau \leqq t\right\}$ is the informed investors' information set at time $t$ and $\mathscr{F}^{u}(t)=\left\{D_{\tau}, P_{\tau}: \tau \leqq t\right\}$ is the uninformed investors' information set. Let $\omega$ be the fraction of the uninformed investors.

Assumption 6. The structure of the economy is common knowledge.

By Assumption 5, we have assumed that investors' information about the state variables can be imperfect. ${ }^{13}$ In addition, we allow investors to differ in their information about the economy. The informed investors have perfect private information about the state variable $\Pi$, while the uninformed investors have no private information. All investors observe the price of the stock and dividends. Although the informed investors do not directly observe $\Theta$, the equilibrium price reveals it to them. ${ }^{14}$ Hence, in the rest of the paper we will utilize this effective equivalence: $\mathscr{F}^{i}(t)=\left\{D_{\tau}, P_{\tau}, \Pi_{\tau}: \tau \leqq t\right\}=$ $\left\{D_{\tau}, P_{\tau}, \Pi_{\tau}, \Theta_{\tau}: \tau \leqq t\right\}$. Given the structure of the market and the economy, $P$ and $D$ are not sufficient to reveal the value of $\Pi$ and $\Theta$ to the uninformed investors. Therefore, information asymmetry persists in equilibrium.

The variable $\omega$, the fraction of uninformed investors, is the key parameter in our model in characterizing the information structure. It captures both imperfect information and asymmetric information. When $\omega=0$, all investors are informed and have perfect information about the state of the economy. When $\omega=1$, all investors are uninformed and have imperfect information about the economy. But there is no information asymmetry among investors. When $\omega \in(0,1)$, both imperfect information and asymmetric information are present in the economy and investors are heterogeneous.

Assumption 7. Investors choose consumption and investment policies in order to maximize expected utilities conditioned on their respective information set, $\boldsymbol{E}\left[\int u(c(\tau), \tau) d \tau \mid \cdot\right]$. All investors have preferences exhibiting constant absolute risk aversion (CARA):

$$
u(c(t), t)=-e^{-\rho t-c(t)},
$$

where $\rho$ is the time-impatience parameter and $c(t)$ is the consumption rate at time $t .^{15}$

The CARA preferences are assumed so that a closed-form solution to the model can be obtained. With CARA preferences, an investor's asset demand is independent of his wealth. ${ }^{16}$ This implies that the equilibrium price of the stock will be independent of the wealth distribution of the investors as well as the level of aggregate wealth. This independence greatly simplifies our problem.

12. This assumption makes the capital market dynamically incomplete in the sense of Harrison and Kreps

13. For earlier work on the optimal portfolio choice and asset prices under imperfect information, see, e.g. Merton (1971), Dothan and Feldman (1986), Detemple (1986), Gennotte (1986).

14. This is true if the equilibrium price is a monotonic function of $\Theta$, which is the case in the linear equilibrium we consider in this paper. Also see the discussion in Section 4. Alternatively, we can assume that $\Theta$ is directly observable to the informed investors.

15. Here, we have assumed that all investors have the same risk aversion with an Arrow-Pratt measure of 1. This is because we want to focus solely on the effect of information on stock prices. This assumption can be easily relaxed as long as we remain in the CARA class. See the discussion in Section 7.

16. With CARA utility, negative consumption and negative wealth are possible. In this paper, we do not impose non-negativity constraints to rule out negative wealth. 
For simplicity in exposition, let $\boldsymbol{b}_{D}=\left(\sigma_{D}, 0,0\right), \boldsymbol{b}_{\Pi}=\left(0, \sigma_{\Pi}, 0\right)$, and $\boldsymbol{b}_{\Theta}=\left(0,0, \sigma_{\Theta}\right)$. Since $w$ is a $(3 \times 1)$ vector of independent standard Wiener processes, innovations in $D$, $\Pi$ and $\Theta$ are independent from each other given the assumed form of $b$ matrices. The three components of $d \underline{w}$ represent respectively the instantaneous shocks to $D, \Pi$ and $\Theta$.

A comment about our notation is in order. We use upper-case letters, Greek or Roman, for state variables and lower-case letters for constants. The upper-case Roman letters usually represent publicly observable variables like price $P$ and dividend rate $D$, while upper-case Greek letter represent variables that are not publicly observable, such as the supply shock $\Theta$. For investors' choice variables such as consumption, stock holdings and wealth, we follow conventional notation.

\section{THE BENCHMARK CASE: PERFECT INFORMATION}

Before we solve the full model specified in the previous section, let us first consider the special case in which all investors are informed (i.e. $\omega=0$ ). This is similar to the case considered by Campbell and Kyle (1988). The equilibrium price under perfect information provides a benchmark about the value of the stock.

Under perfect information, the price of the stock depends only on the primary state variables $D, \Pi$ and $\Theta$. Given the CARA preferences and the linear processes governing $D, \Pi$ and $\Theta$, the price is a linear function of the state variables. Let $P^{*}$ be the equilibrium stock price under perfect information. We have the following result: ${ }^{17}$

Theorem 3.1. Under perfect information, the equilibrium price of the stock is

$$
P^{*}=\Phi+\left(p_{0}^{*}+p_{\Theta}^{*} \Theta\right)
$$

where

$$
\Phi=\boldsymbol{E}_{t}\left[\int_{t}^{\infty} e^{-r t} D(s) d s\right]=\phi+p_{D}^{*} D+p_{\Pi}^{*} \Pi, \quad \phi=\frac{a_{\Pi} p_{\Pi}^{*} \bar{\Pi}}{r}
$$

Here,

$$
p_{D}^{*}=\frac{1}{r+k}, \quad p_{\Pi}^{*}=\frac{p_{D}^{*}}{r+a_{\Pi}}, \quad p_{0}^{*}=-\left[\left(p_{D}^{*}\right)^{2} \sigma_{D}^{2}+\left(p_{\Pi}^{*}\right)^{2} \sigma_{\Pi}^{2}\right]<0 \quad \text { and } \quad p_{\Theta}^{*}<0
$$

$\Phi$ gives the present value of expected future cash flows discounted at the risk-free rate. Risk aversion of the investors increases the expected return to the stock by a simple discount on the price rather than by increasing the discount rate. This is shown by Campbell and Kyle $(1988)$ in a similar set-up. Indeed, $\left(p_{0}^{*}+p_{\Theta}^{*} \Theta\right)\left(p_{0}^{*}, p_{\Theta}^{*}<0\right)$ represents the discount on the price of the stock to compensate for the risk in its future cash flow. This discount increases with $\Theta$, the supply shock of the risky capital, because $\Theta$ determines the total amount of aggregate risk the economy is exposed to. As $\Theta$ increases, each investor has to bear more of the market risk in equilibrium. The price of the stock has to adjust to give a higher expected return in order to induce investors to hold more stocks.

Given the equilibrium price of the stock, the excess return to one share is $d P+D d t-$ $r P d t$, which we denote by $d Q$. Its conditional expectation, i.e. the expected excess return to a share of stock is

$$
\boldsymbol{E}_{t}[d Q]=\left[e_{0}^{*}-\left(r+a_{\Theta}\right) p_{\Theta}^{*} \Theta\right] d t,
$$

17. This is a special case derived from our general model. The proof of this result can be obtained from the solution to the general case, which is provided in the following section. 
where $e_{0}^{*}=-r p_{0}^{*} . e_{0}^{*}$ is the unconditional expected excess return on one share of stock. $e_{0}^{*}$ depends only on $\sigma_{D}$ and $\sigma_{\Pi}$ which characterize the risk associated with future cash flows of the stock. Note that $e_{0}^{*}$ is independent of $\sigma_{\Theta}$. Therefore, the variance of the supply shocks does not affect the unconditional expected excess return, even though it does affect the price volatility. This result contrasts with the result of De Long et al. (1990). It is assumed in De Long et al. that rational investors have finite horizons and have to liquidate their positions at the end of their lifetimes. Since supply shocks cause temporary shifts in price from its "fundamental value", investors with finite lifetime face additional risk in price due to supply shocks when they have to liquidate their stock positions. Hence, they demand extra premium for the additional risk in liquidation prices due to supply shocks. For investors with longer horizons, the effect of the additional risk in liquidation prices due to supply shocks becomes smaller. When investors have infinite horizons, the unconditional expected excess return is determined only by the fundamental risk of the stock which is the risk in its future cash flows. More volatile prices caused by temporary shocks in supply do not change the risk of investing in the stock and the risk premium. As we will see later, this is no longer the case under asymmetric information.

The innovation variance of the stock price (i.e. the variance of instantaneous stock return) is a constant given by $\sigma_{P^{*}}^{2}=p_{D}^{* 2} \sigma_{D}^{2}+p_{\Pi}^{* 2} \sigma_{\Pi}^{2}+p_{\Theta}^{* 2} \sigma_{\Theta}^{2}$. A constant variance of prices implies that the variance of the percentage returns increases as the price of the stock decreases and vice versa (see Campbell and Kyle (1988)). This phenomenon has been noted in U.S. stock market data (see Black (1976), Nelson (1987)).

When both informed and uninformed investors are present in the economy, the situation becomes more complicated. However, we may still expect that the equilibrium price will somewhat resemble the functional form of the price in the benchmark case due to the underlying linearity in the model.

\section{EQUILIBRIUM OF THE ECONOMY}

In this section, we solve for the equilibrium of the economy defined in Section 2. The equilibrium concept is that of rational expectations developed by Lucas (1972), Green (1973), Grossman (1976), and Kreps (1977). The way we obtain an equilibrium of the economy is similar in essence to that of Grossman (1976) and others in static settings. ${ }^{18}$ We first conjecture an equilibrium price function. Based on the assumed price function, we solve the investors' learning and optimization problem. Market clearing is then imposed to verify the conjectured price function. ${ }^{19}$

The equilibrium stock price generally depends on all the state variables of the economy. The primary state variables are the current dividend rate $D$, the short-term stationary level of the dividend $\Pi$ and the aggregate supply shock of the stock $\Theta$. However, when information asymmetry is present these primary state variables are not sufficient to fully characterize the state of the economy. The uninformed investors do not directly observe $\Pi$ and $\Theta$ but can use dividends and prices to infer the true values of $\Pi$ and $\Theta$. Their demand for the stock will depend on the inferred values (estimates) of $\Pi$ and $\Theta$. Therefore, the existence of the uninformed investors introduces new state variables into the economy, such as their estimates of the unobserved variables. We call these new state variables "induced state variables". We can write $P=P(D, \Pi, \Theta, \cdot)$ where "." denotes the induced state variables.

18. Also see Hellwig (1980), Diamond and Verrecchia (1981), and Admati (1985).

19. The uniqueness of equilibrium will not be discussed in this paper. 
The observations of the perfect information case in the previous section suggest the following proposition.

Proposition. For the economy defined by Assumptions 1-7, there exists a stationary rational expectations equilibrium. Let $\hat{\Pi}=E\left[\Pi \mid \mathscr{F}_{t}^{u}\right]$ and $\Delta \equiv \hat{\Pi}-\Pi . \Delta$ represents the uninformed investors' error in estimating $\Pi$. The equilibrium price function has the following linear form:

$$
P=\left(\phi+p_{0}\right)+p_{D}^{*} D+p_{\Pi} \Pi+p_{\Theta} \Theta+p_{\Delta} \hat{\Pi}=\Phi+\left(p_{0}+p_{\Theta} \Theta\right)+p_{\Delta} \Delta,
$$

where $p_{\Pi}=p_{\Pi}^{*}-p_{\Delta}, \Phi$ is given by equation (3.2) and $p_{\Theta}<0$.

Before we proceed with the proof, a few comments about the proposed price function are in order. First, $\hat{\Pi}(t)$ is the conditional expectation of $\Pi(t)$ by the uninformed investors. It depends on the whole history of dividends and prices up to and including time $t$. As we show later, this dependence is linear. Hence, equation (4.1) gives a condensed and implicit form of the price function. Second, given the proposed functional form, the equilibrium price reveals the true value of $\Theta$ to the informed investors. Third, the equilibrium price reveals to the uninformed investors the following sum of $\Pi$ and $\Theta: p_{\Pi} \Pi+p_{\Theta} \Theta$ (since both $D$ and $\hat{\Pi}$ are in $\mathscr{F}^{u}$ ). Define $\Lambda \equiv p_{\Pi} \Pi+p_{\Theta} \Theta$. Then, $P=$ $p_{0}+p_{D}^{*} D+p_{\Delta} \hat{\Pi}+\Lambda$. Hence, $\Lambda$ is the variable that captures the information content of prices. Observing $D$ and $P$ is equivalent to observing $D$ and $\Lambda$. In other words, $\mathscr{F}^{D, P}=\mathscr{F}^{D, \Lambda} .^{20}$ Third, since an uninformed investor's demand of the stock depends on his estimates of the unobserved state variables, $\hat{\Pi}$ is in the price function as an induced state variable. By the same token, one might expect $\hat{\Theta}$, the filter for $\Theta$, to be also in the price function. However, this is unnecessary due to the following lemma:

Lemma 4.1. Given the proposed price function, the filters $\hat{\Pi}$ and $\hat{\Theta}$ satisfy the condition:

$$
p_{\Pi} \hat{\Pi}+p_{\Theta} \hat{\Theta}=p_{\Pi} \Pi+p_{\Theta} \Theta \quad \text { or } \quad p_{\Pi}(\Pi-\hat{\Pi})=-p_{\Theta}(\Theta-\hat{\Theta}) \text {. }
$$

Proof. $E\left[\Lambda \mid \mathscr{F}^{u}\right]=p_{\Pi} \hat{\Pi}+p_{\Theta} \hat{\Theta}$. But $\Lambda \subseteq \mathscr{F}^{u}$. Hence, $E\left[\Lambda(t) \mid \mathscr{F}^{u}(t)\right]=\Lambda(t) . \|$

Therefore, $\hat{\Theta}$ is functionally related to the state variables already included in Eq. (4.1).

The rest of this section provides a proof of the Proposition following the approach specified earlier.

\subsection{The filtering problem of the uninformed investors}

An uninformed investor learns about the values of $\Pi$ and $\Theta$ from his observations of $D$ and $P$. His optimal filter for $\Pi$ and $\Theta$ based on his information set $\mathscr{F}^{u}(t)=\left\{D_{\tau}, P_{\tau}: \tau \leqq t\right\}$ are derived in Appendix A. The results are summarized in the theorem below:

Theorem 4.1. $\hat{\Pi}$ and $\hat{\Theta}$ satisfy the following stochastic differential equations:

$$
\begin{gathered}
\left(\begin{array}{l}
d \hat{\Pi} \\
d \hat{\Theta}
\end{array}\right)=\left[\begin{array}{c}
a_{\Pi}(\bar{\Pi}-\hat{\Pi}) \\
-a_{\Theta} d \hat{\Theta}
\end{array}\right] d t+\left[\begin{array}{ll}
h_{\Pi D} & h_{\Pi \Lambda} \\
h_{\Theta D} & h_{\Theta \Lambda}
\end{array}\right]\left(b_{s} b_{s}^{T}\right)^{1 / 2} d \tilde{w}, \\
d \underline{\tilde{w}}=\left(b_{s} b_{s}^{T}\right)^{-1 / 2}\left[\begin{array}{c}
d D-(\hat{\Pi}-k D) d t \\
d \Lambda-a_{\Pi} p_{\Pi}(\bar{\Pi}-\hat{\Pi}) d t+a_{\Theta} p_{\Theta} \hat{\Theta} d t
\end{array}\right],
\end{gathered}
$$

20. Here, $\mathscr{F}^{z_{1}}, z_{2}, \ldots, z_{n}$ denotes the smallest $\sigma$-algebra with respect to which $\left\{Z_{1}(\tau), Z_{2}(\tau), \ldots, Z_{n}(\tau)\right\}$ is measurable. 
where $h_{\Pi D}(>0), h_{\Pi \Lambda}, h_{\Theta D}(>0), h_{\Theta \Lambda}$ are constants, $b_{s}$ is a $(2 \times 3)$ matrix. The innovation process of the filters, $\tilde{w}$, is a standard Wiener process with respect to $\mathscr{F}^{u}(t) \equiv \mathscr{F}^{D, P}(t)$. Furthermore, the information structure generated by $\mathscr{F}^{\tilde{w}}(t)$ is equivalent to that generated by $\mathscr{F}^{D, P}(t)$.

\section{Proof. See Appendix A. \|}

As specified in equation (2.1), $\Pi$ governs the expected changes in dividends. Not observing $\Pi$, the uninformed investors rationally draw inferences about $\Pi$ from dividends and prices. They rationally attribute a shock in dividend to reflect partially a change in $\Pi$. This gives rise to the positive contribution of dividend shocks to innovations in $\hat{\Pi}$, as shown in equation (4.3). Thus, $\boldsymbol{E}\left[d \hat{\Pi} d D \mid \mathscr{F}_{t}^{u}\right]=h_{\Pi D}>0$ even though $d w_{D}$ and $d w_{\Pi}$ are independent. From equation (4.3), we observe that $\hat{\Theta}$ also positively responds to dividend shocks. For the uninformed investors, a positive innovation in $D$ suggests an increase in $\Pi$. Conditioned on $\Lambda=p_{\Pi} \Pi+p_{\Theta} \Theta$, the increase in $\Pi$ must be offset by an increase in $\Theta$ (given $p_{\Theta}<0$ ). Hence, $\boldsymbol{E}\left[d \hat{\Theta} d D \mid \mathscr{F}_{t}^{u}\right]=h_{\Theta D}>0$ although $\Theta$ and $D$ are independent. The joint esimation of $\Pi$ and $\Theta$ based on both $D$ and $P$ generates the induced correlation between the filters and dividends and prices. The induced correlation between the uninformed investors' estimates and dividends as well as prices are important in understanding the behaviour of stock prices and returns.

Furthermore, the uninformed investors' estimation error, $\Delta=\hat{\Pi}-\Pi$, follows a standard O-U process:

$$
d \Delta=-a_{\Delta} \Delta d t+\boldsymbol{b}_{\Delta} d \underline{w}
$$

where $a_{\Delta}$ is a positive constant and $b_{\Delta}$ is a $(1 \times 3)$ constant matrix given in Appendix A. The fact that $\Delta$ is mean-reverting to zero implies that the estimation errors of the uninformed investors are only temporary. As a matter of fact, the continuous flow of dividends as well as changes in prices provide a flow of new information about the underlying growth rate of dividends and supply shocks. The uninformed investors constantly update their estimates about $\Pi$ (and $\Theta$ ) based on the newly arrived information and correct the errors made in their previous estimation. Suppose that there has been a positive shock in $D$ while there has been no shock to $\Pi$. Not observing $\Pi$, the uninformed investors rationally attribute the dividend shock to partially reflect a high value of $\Pi$, hence increase their estimate $\hat{\Pi}$. However, the future dividend will not grow as expected since $\Pi$ has not increased. When new levels of $D$ are realized, the uninformed investors will revise their estimate and lower $\hat{\Pi}$, eliminating the error in their previous estimation.

\subsection{Investment opportunities}

Given the process of filter $\hat{\Pi}$, the stock price follows the process:

$$
d P=\left[p_{D}^{*}(\Pi-k D)+a_{\Pi} p_{\Pi}^{*}(\bar{\Pi}-\Pi)-a_{\Theta} p_{\Theta} \Theta-a_{\Delta} p_{\Delta} \Delta\right] d t+b_{P} d \underline{w},
$$

where $b_{P}$ is a $(1 \times 3)$ constant matrix as given in Appendix A. In order to characterize investment opportunities in the economy, we consider the instantaneous excess return to one share of stock: $d Q=(D-r P) d t+d P$. $d Q$ is also the return on a zero-wealth portfolio long one share of stock fully financed by borrowing at the risk-free rate. $Q$ gives the undiscounted cumulative cash flow from the zero-wealth portfolio. 
Theorem 4.2. Given the price process in equation (4.6), $Q$ satisfies the stochastic differential equation:

$$
d Q=(D-r P) d t+d P=\left[e_{0}+e_{\Theta} \Theta+e_{\Delta} \Delta\right] d t+b_{P} d \underline{w},
$$

where $e_{0}=-r p_{0}, e_{\Theta}=-\left(r+a_{\Theta}\right) p_{\Theta}$ and $e_{\Delta}=-\left(r+a_{\Delta}\right) p_{\Delta}$.

To the informed investors, $E\left[d Q \mid \mathscr{F}^{i}\right] / d t=e_{0}+e_{\Theta} \Theta+e_{\Delta} \Delta$. The expected excess return on the stock only depends on $\Theta$ and $\Delta$. The level of aggregate stock supply affects the excess return on the stock because it determines the total risk exposure of the economy. The short-run stationary level of dividend $\Pi$ does not affect the excess return per se, but $\Delta$, the uninformed investors' error in estimating $\Pi$, does. When $\Delta>0$, the uninformed investors are over-estimating the future dividend growth, which drives up the price today. Future corrections are expected when information is revealed through new realizations of dividends. Hence, a price drop is expected by the informed investors. Therefore, the return expected by informed investors is negatively related to $\Delta$ (since $e_{\Delta}<0$ ). To the uninformed investors, $E\left[d Q \mid \mathscr{F}^{i}\right] / d t=e_{0}+e_{\Theta} \hat{\Theta}$. Their expected excess return on the stock depends only on $\hat{\Theta}$, their estimate of the supply shock.

Theorem 4.2 simplifies the investors' optimization problems which we turn to next. Since the expected return on the stock is governed by $\Theta$ and $\Delta$, both following univariate processes, they fully determine the investment opportunities of the economy. ${ }^{21}$

\subsection{The informed investors' optimization problem}

Let $W^{i}$ be an informed investor's wealth, $X^{i}$ his holding of the stock and $c^{i}$ his consumption. His optimization problem is

$$
\operatorname{Max}_{X^{i}, c^{i}} E\left[-\int_{t}^{\infty} e^{-\rho s-c^{i}(s)} d s \mid \mathscr{F}_{t}^{i}\right] \text { s.t. } d W^{i}=\left(r W^{i}-c^{i}\right) d t+X^{i} d Q .
$$

Let $J^{i}\left(W^{i} ; \Theta, \Delta ; t\right)$ be the value function where $\Theta$ and $\Delta$ are the two state variables that govern the investment opportunities. $J^{i}$ satisfies the following Bellman equation: ${ }^{22}$

$$
\begin{aligned}
0=\operatorname{Max}_{c^{i}, X^{i}}\left\{-e^{-\rho t-c^{i}}+E\left[d J^{i}\left(W^{i} ; \Theta, \Delta ; t\right) \mid \mathscr{F}^{i}(t)\right] / d t\right\} \\
\text { s.t. } d W^{i}=\left(r W^{i}-c^{i}\right) d t+X^{i} d Q, \\
\quad \lim _{\tau \rightarrow \infty} E\left[J^{i}\left(W^{i} ; \Theta, \Delta ; t+\tau\right) \mid \mathscr{F}^{i}(t)\right]=0 .
\end{aligned}
$$

The solution is provided in the following theorem: ${ }^{23}$

Theorem 4.3. Equation (4.9) has a solution of the form:

$$
J^{i}\left(W^{i} ; \Theta, \Delta ; t\right)=-e^{-\rho t-r W^{i}-V^{i}(\Theta, \Delta)} .
$$

Here, $V^{i}(\Theta, \Delta)$ is a quadratic function: $V^{i}(\Theta, \Delta)=\frac{1}{2} \underline{\Psi}^{i T} v^{i} \underline{\Psi}^{i}$, where $\underline{\Psi}^{i T}=(1, \Pi, \Delta)$. The optimal demand of the stock is a linear function of $\Theta$ and $\Delta$ :

$$
\boldsymbol{X}^{i}=\boldsymbol{f}^{i} \underline{\Psi}^{i}
$$

Here, $v^{i}$ and $f^{i}=\left(f_{0}^{i}, f_{\Theta}^{i}, f_{\Delta}^{i}\right)$ are respectively $(3 \times 3)$ and $(1 \times 3)$ constant matrices.

\section{Proof. See Appendix B. \|}

21. The risk-free rate is assumed to be constant.

22. We assume that $J^{i}$ is twice differentiable in its variables.

23. This problem is similar to the one solved by Merton (1971). The difference is that here we have two state variables governing the excess returns on the stock while Merton considers the single-variable case. 


\subsection{The uninformed investor's optimization problem}

Let $W^{u}$ be an uninformed investor's wealth, $X^{u}$ his holding of the stock and $c^{u}$ his consumption. His optimization problem is

$$
\operatorname{Max}_{X^{u}, c^{u}} E\left[-\int_{t}^{\infty} e^{-\rho s-c^{u}(s)} d s \mid \mathscr{F}_{t}^{u}\right] \quad \text { s.t. } d W^{u}=\left(r W^{u}-c^{u}\right) d t+X^{u} d Q .
$$

The solution to the optimization problem can, in general, be complicated. The uninformed investor's consumption-investment policy is a function of their information set, which contains the whole history of dividends and prices. Given the processes assumed for the primary state variables as well as the price, however, the information structure generated by $\mathscr{F}^{u}(t)$ has an equivalent representation which is the one generated by $\tilde{\tilde{w}}$. Here, $\underline{\tilde{w}}$ is the innovation process of the filters which is a Wiener process with respect to $\mathscr{F}^{u}$. The filters provide a sufficient statistic for $\mathscr{F}^{u}(t)$. Using this equivalent representation of the information structure, we can restate the uninformed investor's optimization problem as a standard Markovian one with the filters being the effective state variables and the innovation process $\underline{\tilde{w}}$ generating the dynamics. It is then formally similar to the informed investors' problem. Thus, we have a situation in which the Separation Principle applies. ${ }^{24}$

Let $J^{u}\left(W^{u} ; \hat{\Theta} ; t\right)$ be the value function. Since $E\left[\Delta \mid \mathscr{F}^{u}\right]=0$, from equation (4.7) the expected excess return of an uninformed investor is determined only by $\hat{\Theta}$. Thus, his value function only depends on $\hat{\Theta}$ in addition to his wealth and time. $J^{u}$ satisfies the following Bellman equation:

$$
\begin{aligned}
& 0= \operatorname{Max}_{c^{u}, X^{u}}\left\{-e^{-\rho t-c^{u}}+E\left[d J^{u}\left(W^{u} ; \hat{\Theta} ; t\right) \mid \mathscr{F}^{u}(t)\right] / d t\right\} \\
& \text { s.t. } d W^{u}=\left(r W^{u}-c^{u}\right) d t+X^{u} d Q \\
& \quad \lim _{\tau \rightarrow \infty} E\left[J^{u}\left(W^{u} ; \hat{\Theta} ; t+\tau\right) \mid \mathscr{F}^{u}(t)\right]=0 .
\end{aligned}
$$

The solution to equation (4.13) is given in Theorem 4.4 .

Theorem 4.4. The program given by equation (4.13) has a solution of the form

$$
J^{u}\left(W^{u} ; \hat{\Theta} ; t\right)=-e^{-\rho t-r W^{u}-V^{u}(\hat{\Theta})},
$$

where $V^{u}(\hat{\Theta})=\frac{1}{2} \underline{\Psi}^{u T} v^{u} \underline{\Psi}^{u}, \underline{\Psi}^{u T}=(1, \hat{\Theta})$. The optimal demand of the stock is

$$
X^{u}=\boldsymbol{f}^{u} \underline{\Psi}^{u}
$$

Here, $\boldsymbol{v}^{u}$ and $f^{u}=\left(f_{0}^{u}, f_{\Theta}^{u}\right)$ are respectively $(2 \times 2)$ and $(1 \times 2)$ constant matrices.

\section{Proof. See Appendix B. \|}

\subsection{Market clearing}

Under the assumed form of the price function, the demand of stock by individual informed and uninformed investors is given respectively by equation (4.11) and (4.15). When the market clears, they must sum to $1+\Theta$. Thus

$$
(1-\omega)\left[f_{0}^{i}+f_{\Theta}^{i} \Theta+f_{\Delta}^{i} \Delta\right]+\omega\left[f_{0}^{u}+f_{\Theta}^{u} \hat{\Theta}\right]=1+\Theta .
$$

24. The Separation Principle states that under certain conditions, the optimal control problem with partial observed state variables can be solved in two stages: first solve for the optimal estimation problem for unobserved variables and then solve the control problem using the estimates as the state variables. For a detailed discussion on the Separation Principle, see Fleming and Rishel (1975). 
Using equation (4.3), we have the following equations:

$$
\begin{gathered}
1=(1-\omega) f_{0}^{i}+\omega f_{0}^{u}, \\
1=(1-\omega) f_{\Theta}^{i}+\omega f_{\Theta}^{u}, \\
0=(1-\omega) p_{\Theta} f_{\Delta}^{i}-\omega p_{\Pi} f_{\Theta}^{u} .
\end{gathered}
$$

The solution to equation (4.17-4.19) determines the coefficients $p_{0}, p_{\Theta}, p_{\Delta}$ in the price function. $^{25}$ This completes our proof of the Proposition. ${ }^{26}$

\section{PRICE VARIABILITY, RISK PREMIUM AND RETURN AUTOCORRELATION}

In what follows, we analyze how the underlying information structure affects stock prices, the risk premium, price volatility and serial correlation in returns.

In the current model, the parameter $\omega$ characterizes the information structure of the economy. Most of the comparative static analysis is concerned with the effect of changing $\omega$. As discussed in Section 2, $\omega$ captures two aspects of the information structure of our model. One aspect is the imperfection in some investor's information. As $\omega$ increases, more investors have imperfect information and the total amount of information in the market decreases. The other aspect is information asymmetry. As $\omega$ changes, the extent to which information is asymmetric among investors also changes. For example, when $\omega$ is slightly less than 1 the investors are no longer homogeneous and information is asymmetric among them. Hence, as we change $\omega$ we are changing these two aspects of the information structure at the same time. The net effect will be the sum of the two. The effect of imperfect information is best illustrated by comparing the two extreme cases: $\omega=0$ and $\omega=1$. The former corresponds to the case of perfect information while the latter the case of pure imperfect information. Comparing the result for $\omega$ in the vicinity of the extreme case ( $\omega=0$ or 1 ) with the extreme case illustrates the effect of information asymmetry.

\subsection{Stock prices}

As stated in the Proposition in Section 4, the equilibrium price of the stock is

$$
P=\Phi+\left(p_{0}+p_{\Theta} \Theta\right)+p_{\Delta} \Delta .
$$

where $\Phi$ is given in Theorem 3.1.

Two extreme cases deserve our attention: the benchmark case of $\omega=0$ in Section 3 and the case when $\omega=1$, i.e. when all investors are uninformed. When $\omega=0$, the equilibrium price is $P^{*}=\left(\phi+p_{0}^{*}\right)+p_{D}^{*} D+p_{\Pi}^{*} \Pi+p_{\Theta}^{*} \Theta$ as derived in Section 3. Let $P^{* *}$ be the equilibrium price when $\omega=1$. In this case, $\Pi$ drops out of the price function since it is not in any investors' information set and in equilibrium the price reveals the true value of $\Theta . P^{* *}$ has the following form:

$$
P^{* *}=\left(\phi+p_{0}^{* *}\right)+p_{D}^{*} D+p_{\Pi}^{*} \hat{\Pi}+p_{\Theta}^{* *} \Theta,
$$

where $p_{0}^{* *}$ and $p_{\Theta}^{* *}$ are the solutions to equation (4.17-4.19) when $\omega=1$. It can be shown that $p_{0}^{* *}<p_{0}^{*}<0$ and $p_{\Theta}^{* *}<0$.

25. Equation (4.17-4.19) is a set of algebraic equations. The proof of existence of a solution is available from the author on request.

26. We do not have an analytical form of the solution to equations (4.17-4.19). Numerical solutions are used in most of the analysis to follow. 
In the general case that $\omega \in[0,1]$, we can show that $p_{\Theta}<0$ and $0 \leqq p_{\Delta} \leqq p_{\Pi}^{*}$. Figures 1.1-1.3 show respectively the coefficient $p_{0}, p_{\Delta}$ and $p_{\Theta}$ as discussed in Section $3, p_{0}$ represents the discount on the price to compensate the risk in future cash flows. $p_{0}$ is negative and decreases with $\omega$. Figure 1.1 further shows that in the limiting case of $\omega=0$ or $\omega=1, p_{0}$ is independent of $\sigma_{\Theta}$. We will discuss the behaviour of $p_{0}$ in more detail in Section 5.3.

$p_{\Delta}$ monotonically increases with $\omega$ as shown in Figure 1.2. It takes the value of 0 when $\omega=0$. In this case, all investors are informed and $\Delta$ does not enter the price function. When $\omega=1, p_{\Delta}=p_{\Pi}^{*}$. $\Pi$ drops out of the price function and only $\hat{\Pi}$ remains. The $p_{\Delta}-\omega$ relation shown in Figure 1.2 is robust to changes in values of the parameters.

$p_{\Theta}$ determines the sensitivity of stock price to supply shocks. As $\omega$ decreases from 1 , there are more informed investors and more information about the stock's future payoffs is available in the market. This reduces the uncertainty in investing in the stock. Less premium is required by the market in absorbing the supply shocks. Hence, $\left|p_{\Theta}\right|$ should decrease as $\omega$ decreases from 1 . This is clearly illustrated by the fact that $\left|p_{\Theta}^{* *}\right|>\left|p_{\Theta}^{*}\right|$. However, the existence of informed investors introduces information asymmetry among investors. The uninformed investors face the risk of being taken advantage of by the informed investors. They demand a higher premium in taking positions against the supply shocks. This causes the price to be more sensitive to changes in aggregate supply and $\left|p_{\Theta}\right|$ to increases as $\omega$ decreases from 1 . The interaction of these two effects

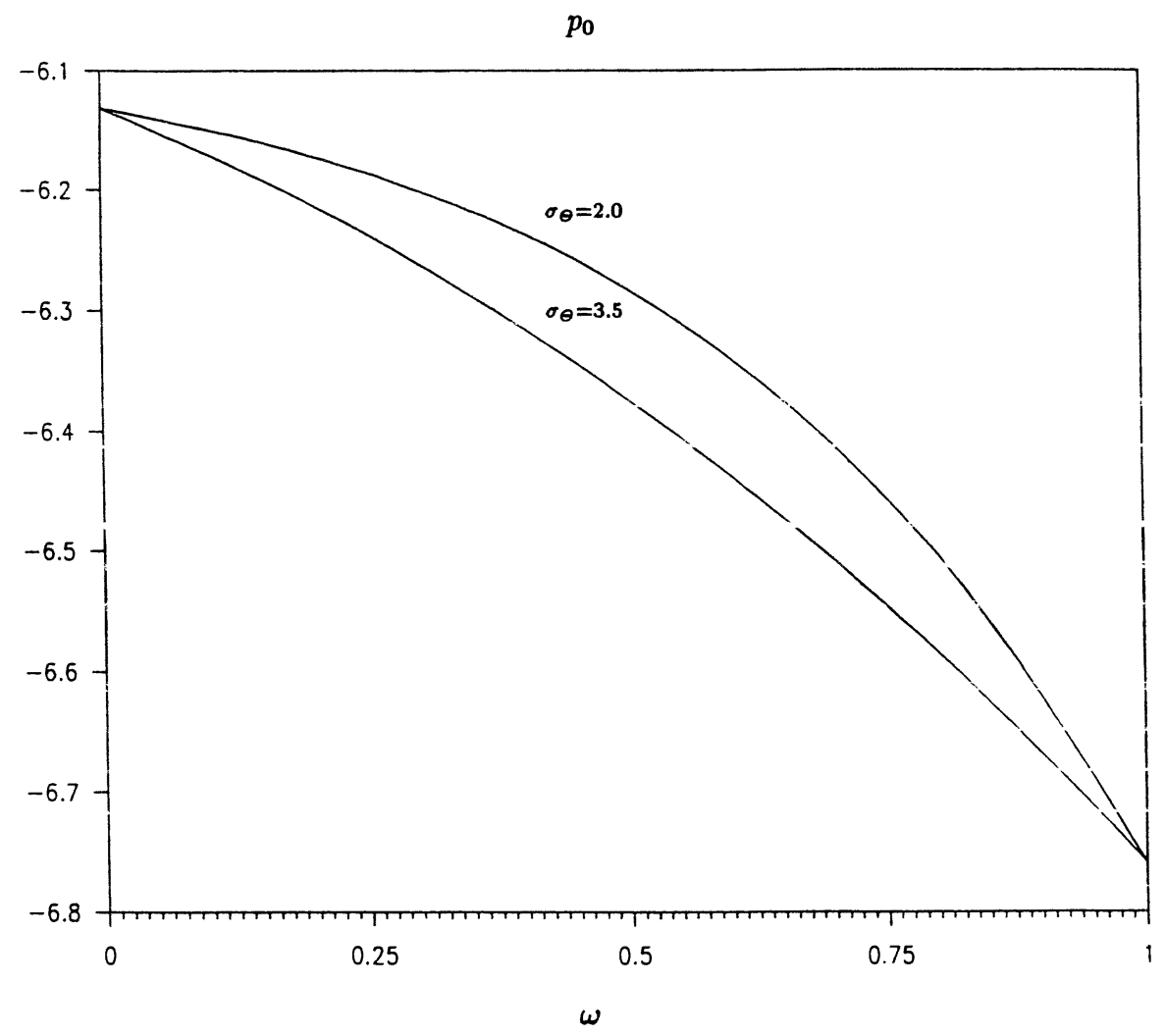

Figure 1.1

$p_{0}$ plotted against $\omega . r=0 \cdot 05, \rho=0 \cdot 2, \bar{\Pi}=0 \cdot 85, k=1 \cdot 0, \sigma_{D}=1 \cdot 0, \sigma_{\Pi}=0 \cdot 6, a_{\Pi}=0 \cdot 2, a_{\Theta}=0 \cdot 4$ 


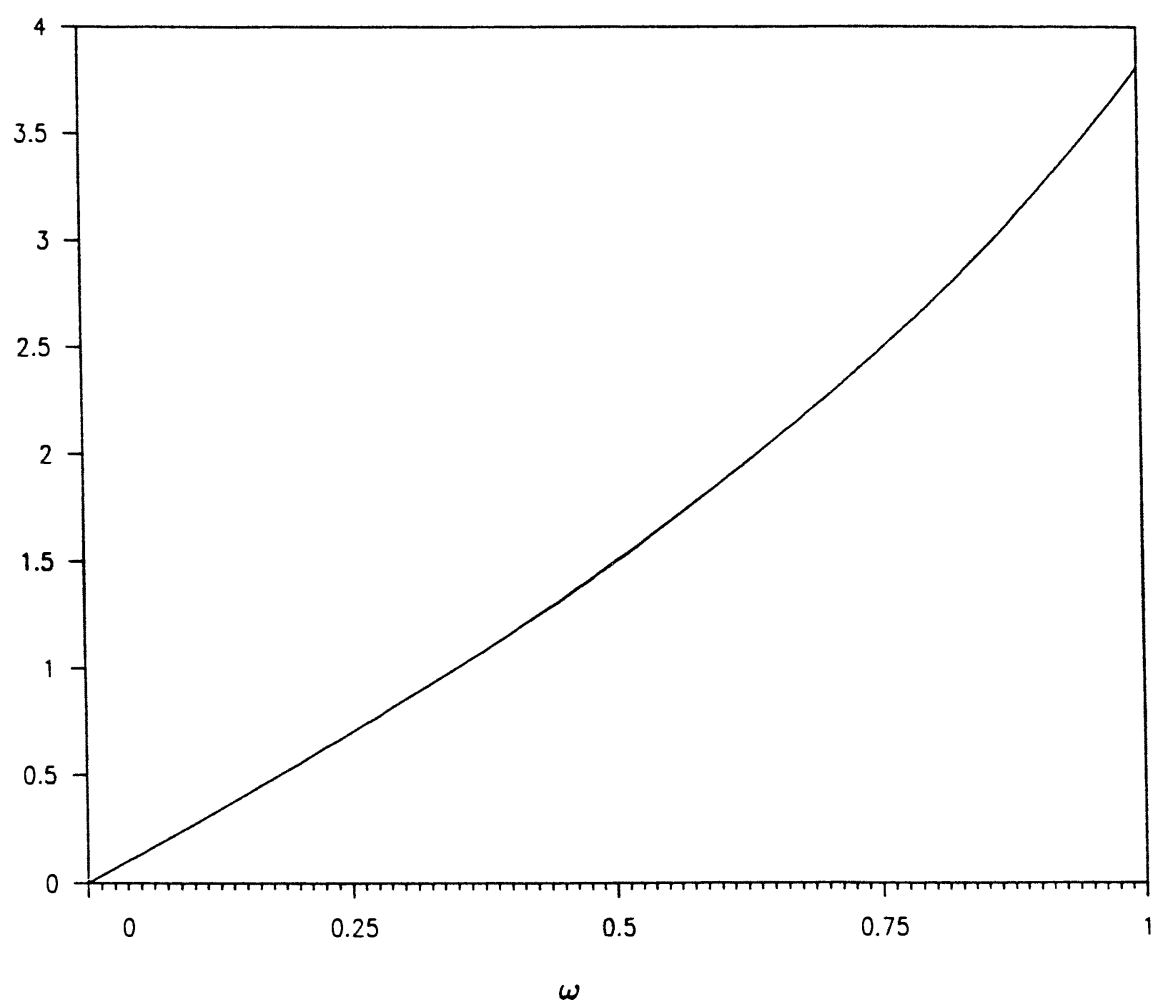

FIGURE 1.2

$p_{\Delta}$ plotted against $\omega . r=0 \cdot 05, \rho=0 \cdot 2, \bar{\Pi}=0 \cdot 85, k=1 \cdot 0, \sigma_{D}=1 \cdot 0, \sigma_{\Pi}=0 \cdot 6, \sigma_{\Theta}=3 \cdot 0, a_{\Pi}=0 \cdot 2, a_{\Theta}=0 \cdot 4$

can give rise to a non-monotonic relation between $p_{\Theta}$ and $\omega$ as shown in Figure 1.3 for some parameter values.

A few comments are in order on the choice of parameter values in Figures 1.1-1.3 and the figures to follow. The parameter values are chosen somewhat arbitrarily. Our purpose here is to show the qualitative relation between the behaviour of stock prices and the underlying information structure. We make no attempt to match the parameters with historic data. ${ }^{27}$ We try to use a consistent set of parameter values for most of the figures. We also vary the parameter values within a wide range and find that most of the figures are robust in their qualitative features. In the cases that the pattern does change with the parameters, different patterns corresponding to different parameter values will be shown or discussed. ${ }^{28}$

The existence of uninformed investors causes deviations in the stock price from its benchmark value under perfect information $P^{*}$.

$$
P-P^{*}=p_{\Delta} \Delta+\left[\left(p_{0}+p_{\Theta} \Theta\right)-\left(p_{0}^{*}+p_{\Theta}^{*} \Theta\right)\right] .
$$

27. Campbell and Kyle (1988) estimated a model that is similar to our benchmark case. Using some of their estimates, we get patterns similar to the ones shown here.

28. In a few figures, we use parameter values different from the ones for most of the other figures. The only reason for doing so is to make the pattern look somewhat more prominent. 


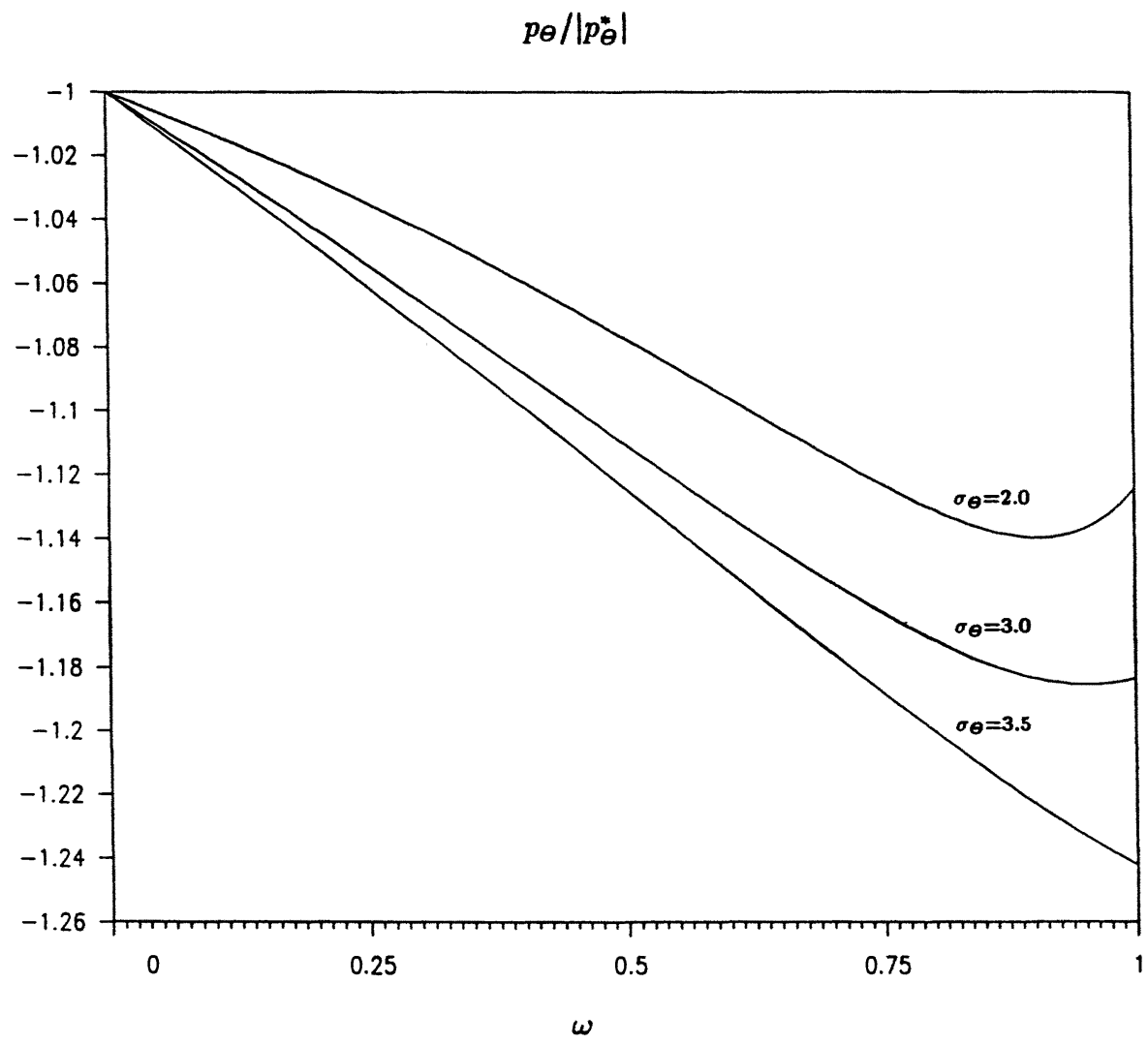

FIGURE 1.3

$p_{\Theta} /\left|p_{\Theta}^{*}\right|$ plotted against $\omega . r=0 \cdot 05, \rho=0 \cdot 2, \bar{\Pi}=0 \cdot 85, k=1 \cdot 0, \sigma_{D}=1 \cdot 0, \sigma_{\Pi}=0 \cdot 6, a_{\Pi}=0 \cdot 2, a_{\Theta}=0 \cdot 4 . p_{\Theta}^{*}$ is the value of $p_{\Theta}$ when $\omega=0$. $p_{\Theta}^{*}=-0.803,-1 \cdot 080,-1 \cdot 421$ when $\sigma_{\Theta}=2 \cdot 0,3 \cdot 0,3 \cdot 5$ respectively.

The difference between $P$ and $P^{*}$ can be broken down into two parts. The first part, $p_{\Delta} \Delta$, is directly caused by the estimation errors of the uninformed investors. With $p_{\Delta}$ being positive, the equilibrium price responds positively to the estimation errors of the uninformed investors. The uninformed investors' optimism drives the price up and their pessimism drives the price down. Although the informed investors have perfect information about the errors of the uninformed investors, their risk-aversion prevents them from taking significantly large positions to eliminate these deviations. Since $\Delta$ follows an O-U process and reverts to a zero mean, $p_{\Delta} \Delta$ represents a temporary component in price deviations. The second part is given by the difference between $\left(p_{0}+p_{\Theta} \Theta\right)$ and $\left(p_{0}^{*}+p_{\Theta}^{*} \Theta\right)$. We pointed out earlier that $\left(p_{0}+p_{\Theta} \Theta\right)$ gives the discount in price in order to compensate for the risk of investing in the stock. Hence, $\left[\left(p_{0}+p_{\Theta} \Theta\right)-\left(p_{0}^{*}+p_{\Theta}^{*} \Theta\right)\right]$ represents a permanent shift in the stock price from its bench-mark value. Indeed, this second component has a non-zero long-run stationary level of $\left(p_{0}-p_{0}^{*}\right)$. As we will see later, the permanent component in the price deviation has to do with the fact that the imperfect information of some investors affects the risk of investing in the stock for these investors.

Another feature of the equilibrium price is its history dependence. Since the uninformed investors do not have perfect information about the state of the economy, their expectations are based upon past as well as present prices and dividends. The private 
information of the informed investors is not fully revealed by the current price. It is gradually revealed by the path of prices as well as dividends through the continuous trading among investors. The uninformed investors' expectation of future returns, and hence their trading strategies will depend on past prices and dividends. This is a direct result of information asymmetry in the current model. ${ }^{29}$

\subsection{Price variability}

Let us consider how the information structure affects the variability of prices in the current model. Two measures of price variability are often used: one is the instantaneous variance of the price (i.e. the innovation variance which is also the variance of instantaneous returns) and the other is the unconditional variance (i.e. volatility). The instantaneous variance is important in analyzing trading strategies while the unconditional variance is often used in empirical testing. We will examine the two separately.

As mentioned earlier, there are two aspects of our information structure: imperfect information and asymmetric information. In order to illustrate how the effect of imperfect information, we compare the limiting case in which all investors are uninformed $(\omega=1)$ with the perfect information case $(\omega=0)$. There is no information that all investors have about future cash flow. Hence, the difference in price variability between these two cases is solely due to the effect of imperfect information. In order to analyze the effect of information asymmetry, we compare the result for $\omega$ close to 1 with the extreme case of $\omega=1$.

Let us first consider the innovation variance of the stock price. The process of the equilibrium stock price is given in equation (4.6). The innovation variance is constant:

$$
\sigma_{P}^{2}=\left(p_{D}^{*}+h_{\Pi D} p_{\Delta}\right)^{2} \sigma_{D}^{2}+\left(1+h_{\Pi \Lambda} p_{\Delta}\right)^{2} \sigma_{\Lambda}^{2},
$$

where $\sigma_{\Lambda}^{2}=p_{\Pi}^{2} \sigma_{\Pi}^{2}+p_{\Theta}^{2} \sigma_{\Theta}^{2}$.

For simplicity, consider the special case when there are no supply shocks, i.e. $\sigma_{\Theta}=0$. In the case of perfect information,

$$
\sigma_{P^{*}}^{2}=p_{D}^{* 2}\left[\sigma_{D}^{2}+\frac{1}{\left(1+a_{\Pi}\right)^{2}} \sigma_{\Pi}^{2}\right] .
$$

The innovation variance of the price comes from the contribution of innovations to dividends and innovations to the dividend growth rate. The two innovatins are independent of each other. In the case of purely imperfect information (i.e. $\omega=1$ ), we have

$$
\sigma_{P^{* *}}^{2}=\left[1+\frac{1}{1+\alpha_{\Pi}}\left(\sqrt{a_{\Pi}^{2}+\left(\sigma_{\Pi}^{2} / \sigma_{D}^{2}\right)}-a_{\Pi}\right)\right]^{2} p_{D}^{* 2} \sigma_{D}^{2}
$$

Clearly,

$$
\sigma_{P^{* *}}^{2}>\sigma_{P^{*}}^{2}
$$

Since now price contains no private information about the stock's future cash flow, investors only extract information about dividend growth from realized dividends. A shift in $D$ not only changes the current dividend payments, but also changes investors' expectations about future dividend growth which is the information effect of dividends.

29. Brown and Jennings (1989) consider a 3-period model with features similar to the current model and analyze the information role of past prices in the context of technical analysis. Our model provides a somewhat more general framework except that its information structure is different from theirs. We have a hierarchic information structure while Brown and Jennings have a symmetric one. 
In this case, innovations to dividends and innovations to expected dividend growth rate are perfectly correlated. Since the stock price increases with both current and expected future dividend growth, the information impact of dividends enhances the sensitivity of the price to changes in the current dividend. Small changes in the current dividend can generate large changes in the price. This increases the innovation variance of the price. Therefore, in the current model when investors have more information about the stock's future cash flow the instantaneous price variability increases.

Now let us consider the effect of information asymmetry on the innovation variance of the price. Note that as $\omega$ increases, $\sigma_{P}^{2}$ does not always increase monotonically. As shown in Figure 2, $\sigma_{P}^{2}$ may peak at some $\omega$ in the interior of $[0,1]$. Since the instantaneous variance of price monotonically decreases with the amount of public information in our model, the non-monotonicity in the $\sigma_{P}^{2}-\omega$ relation reflects the effect of information asymmetry.

It has often been argued in the literature that rational investors with superior information should always stabilize prices. ${ }^{30}$ The basic reason is that better informed

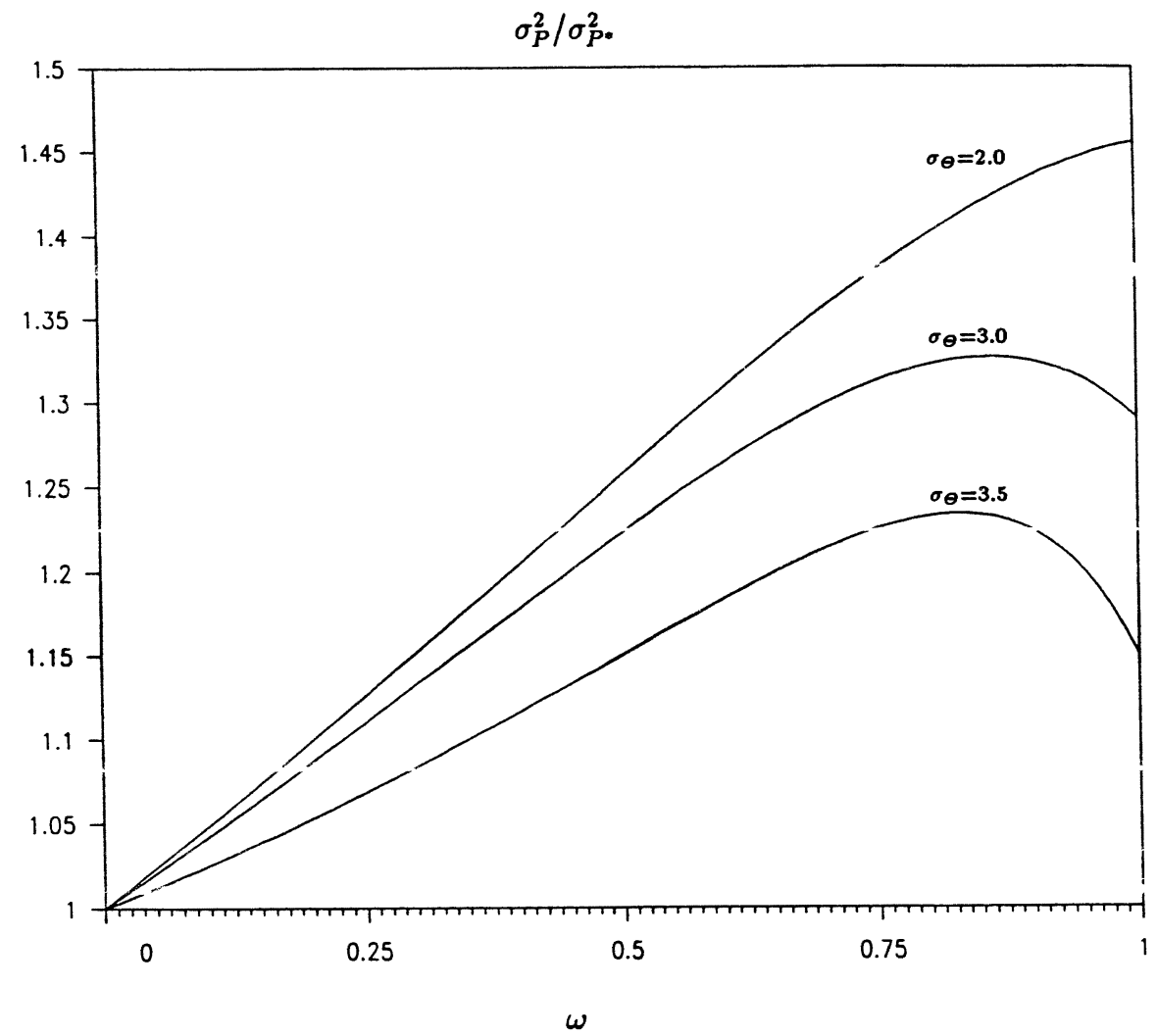

Figure 2

$\sigma_{P}^{2} / \sigma_{P^{*}}^{2}$ plotted against $\omega . r=0 \cdot 05, \rho=0 \cdot 2, \bar{\Pi}=0 \cdot 85, k=1 \cdot 0, \sigma_{D}=1 \cdot 0, \sigma_{\Pi}=0 \cdot 6, a_{\Pi}=0 \cdot 2, a_{\Theta}=0 \cdot 4 . \sigma_{P^{*}}^{2}$ is the conditional variance of price when $\omega=0 . \sigma_{P^{*}}^{2}=8 \cdot 710,16 \cdot 635,30 \cdot 875$ when $\sigma_{\Theta}=2 \cdot 0,3 \cdot 0,3 \cdot 5$ respectively.

30. De Long et al. (1990) argue that if there exist investors in the market who follow, by assumption, certain positive feedback strategies, the introduction of rational speculators can actually destabilize prices. Our model differs from theirs in that here all investors' investment strategies are directly derived from utility maximization. Information asymmetry is explicitly modelled to generate the result. 
investors take profitable positions whenever price deviates from the fundamentals. By doing so, they partially reveal their private information to the market and move the price towards its "fundamental value". The more of these informed investors, the larger the impact they have on the price and the less it can deviate from its "fundamental value". Hence, increasing the fraction of informed investors should reduce price variability.

Given the current information structure, it is not the case that informed investors always stabilize prices and reduce price variability. To see why, let us look at the vicinity of $\omega=1$. When $\omega=1$, investors are homogeneous and all uninformed. The absence of information asymmetry enables investors to perfectly infer the level of supply shock from the equilibrium price. In other words, the fact that "nobody knows anything" enables everybody to know something. Now suppose that a small fraction of informed investors is introduced into the market (i.e. $\omega$ is slightly less than 1). On the one hand, the informed investors bring in more information about dividend growth through their demand and prices. This has the effect of reducing instantaneous price variability since the uninformed investors now have better information about $\Pi$ and are less reliant on dividends in learning about $\Pi$. Also, better information about $\Pi$ reduces the uncertainty in future cash flows. Hence, the premium demanded by the uninformed investors in accommodating supply shocks decreases, which also reduces the instantaneous price variability. On the other hand, since the uninformed investors use prices to filter future dividend growth rate, innovations to the aggregate supply will be correlated with innovations to the dividend growth expected by the uninformed investors. An increase in price due to a decrease in $\Theta\left(p_{\Theta}<0\right)$ is rationally interpreted as partially reflecting an increase in $\Pi$. This is fed back into the price through the uninformed investors' demand and causes the price to increase further. Furthermore, when there exist informed investors, the uninformed investors face the adverse selection problem in accommodating the supply shocks. They bear the risk of trading with those investors with superior information. Higher premia are required by the uninformed investors to absorb supply shocks. ${ }^{31}$ This also causes price to be more sensitive to changes in aggregate supply and increases instantaneous price variability. The net effect of increasing the fraction of informed investors is determined by these two off-setting forces. For some parameter values, the efnect of information asymmetry dominates. When more informed investors are introduced in the market, the price can become more volatile. Figure 2 gives examples of this situation.

We now examine the relation between information structure and the unconditional variance of the stock price. When $a_{\Pi}, a_{\Theta}$ and $k$ are strictly positive, the price of the stock has a finite unconditional variance. The unconditional variance of $P, \operatorname{Var}[P]$, is calculated in Appendix C.

In order to consider the effect of imperfect information on price volatility, compare again the two extreme cases: $\omega=0$ and $\omega=1$.

First, suppose that there are no supply shocks (o.e. $\sigma_{\Theta}=0$ ). When $\omega=1$ (all investors are uninformed), $P=P^{* *}$ and

$$
\operatorname{Var}\left[P^{* *}\right]=\operatorname{Var}\left[p_{D}^{*} D+p_{\Pi}^{*} \hat{\Pi}\right] .
$$

When $\omega=0$ (all investors are informed), $P=P^{*}$. Note that

$$
P_{t}^{*}=\mathbf{E}\left[P_{t}^{*} \mid \mathscr{F}_{t}^{u}\right]-p_{\Pi}^{*}\left(\hat{\Pi}_{t}-\Pi_{t}\right) .
$$

Hence,

$$
\operatorname{Var}\left[P^{*}\right]=\operatorname{Var}\left[P^{* *}\right]+p_{\Pi}^{* 2} \operatorname{Var}[\Delta] \geqq \operatorname{Var}\left[P^{* *}\right] .
$$

31. As shown in Figure $1.3, p_{\Theta}$ can become more negative as $\omega$ decreases from 1. 
The price becomes more volatile when investors have more information about the stock's cash flow. This case is closely related to the discussion of West (1988). Figure 3 shows that the unconditional variance of the price monotonically decrease with $\omega$ when $\sigma_{\Theta}$ is small. $^{32}$

When there are supply shocks, the situation is different. Supply shocks contribute to price volatility since they affect the price. When investors are less informed, there is more uncertainty in the stock's future cash flow and investors demand higher premium on the stock. Therefore, $\left|p_{\Theta}^{* *}\right|>\left|p_{\Theta}^{*}\right|$ as shown by Figure 1. The price is more sensitive to supply shocks when investors have less information. Increasing price elasticity to supply shocks causes the price to be more volatile. Formally, we have

$$
\operatorname{Var}\left[P^{*}\right]-\operatorname{Var}\left[P^{* *}\right]=p_{\Pi}^{* 2} \operatorname{Var}[\Delta]-\left(p_{\Theta}^{* * 2}-p_{\Theta}^{* 2}\right) \operatorname{Var}[\Theta]
$$

Since $p_{\Theta}^{* *^{2}}-p_{\Theta}^{* 2}>0, \operatorname{Var}\left[P^{*}\right]-\operatorname{Var}\left[P^{* *}\right]$ can be negative when $\operatorname{Var}[\Theta]$ is large. ${ }^{33}$

\section{$\operatorname{Var}[P] / \operatorname{Var}\left[P^{*}\right]$}

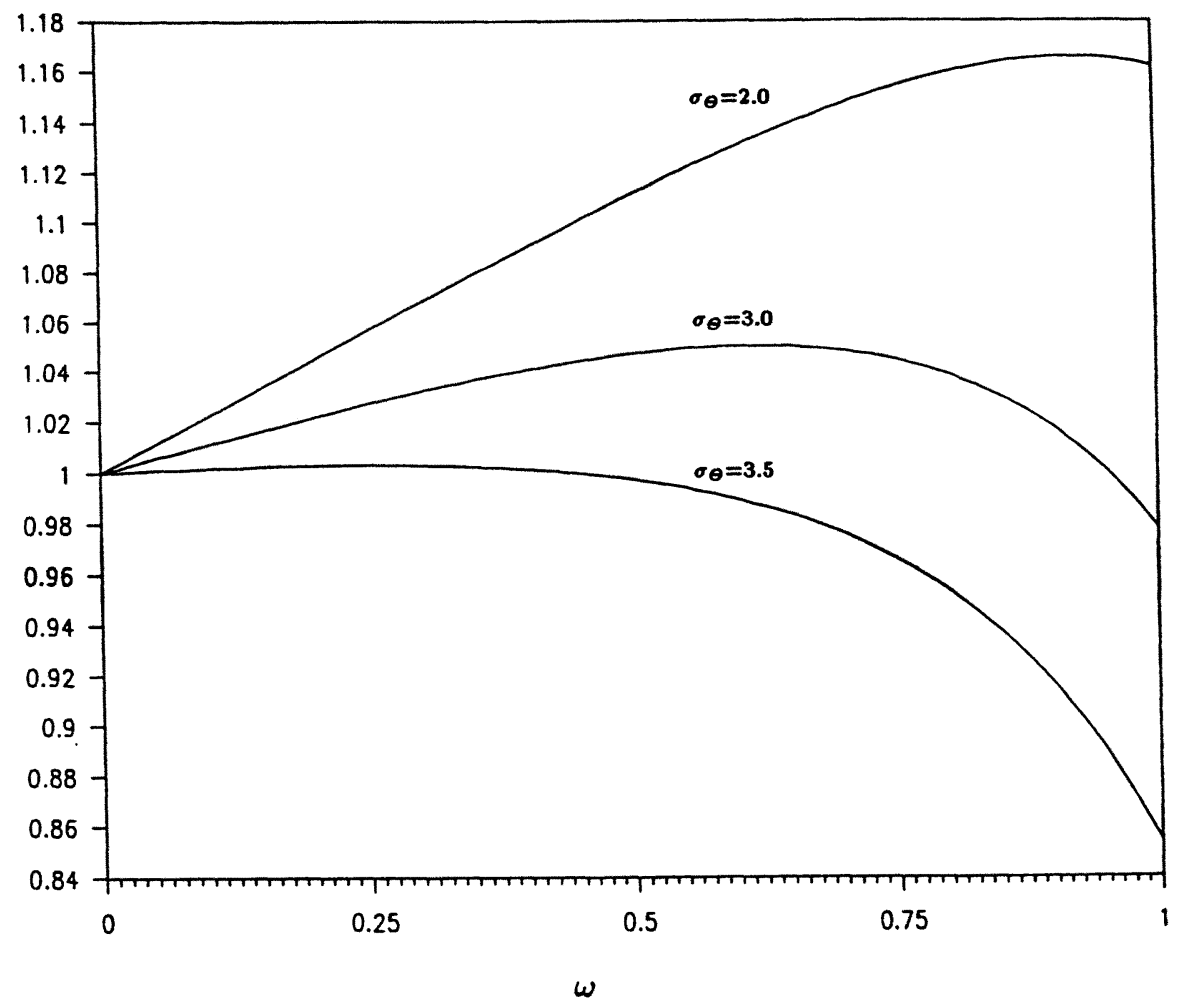

FIGURE 3

$\operatorname{Var}[P] / \operatorname{Var}\left[P^{*}\right]$ plotted against $\omega . r=0 \cdot 05, \rho=0 \cdot 2, \bar{\Pi}=0 \cdot 85, k=1 \cdot 0, \sigma_{D}=1 \cdot 0, \sigma_{\Pi}=0 \cdot 6, a_{\Pi}=0 \cdot 2, a_{\Theta}=0 \cdot 4$. $\operatorname{Var}\left[P^{*}\right]$ is the unconditional variance of price when $\omega=0$. $\operatorname{Var}\left[P^{*}\right]=31 \cdot 2,47 \cdot 1,64 \cdot 9$ when $\sigma_{\Theta}=2 \cdot 0,3 \cdot 0,3 \cdot 5$ respectively

32. The similar monotonic pattern is obtained when $\sigma_{\Pi}$ or $a_{\circledast}$ is large. The former case corresponds to high variability in $\Pi$. The later case corresponds to short lived supply shocks.

33. In the case that $\sigma_{\Theta}$ is large, or $a_{\Theta}$ small,or $a_{\Pi}$ small, the price volatility becomes monotonically increasing with $\omega$. 
It is shown in Figure 3 that $\operatorname{Var}[P]$ can behave in a similar fashion to $\sigma_{P}^{2}$ when $\omega$ changes. The non-monotonicity in the $\operatorname{Var}[P]-\omega$ relation is partially due to information asymmetry among investors as discussed in the case of conditional variance.

In various price volatility tests of stock market efficiency (e.g. LeRoy and Porter (1981), Shiller (1981)), equilibrium stock prices are obtained by assuming the existence of a representative investor with homogeneous information. The effect of information asymmetry has not been taken into consideration. Our model shows that information asymmetry can cause price to be more variable. The traditional models of homogeneous investors may understate price volatility. ${ }^{34}$

\subsection{Risk premium}

The risk premium on the stock is given by $\varepsilon \equiv e / P$ where we only consider the situation when $P>0$. $e$ is the expected excess return on the stock given by

$$
e=e_{0}+e_{\Theta} \Theta+e_{\Delta} \Delta
$$

Clearly, $\varepsilon$ is not constant over time and its instantaneous level depends on all the state variables. Let us look at the "long-run level" $\bar{\varepsilon}$ defined by $\bar{\varepsilon}=\bar{e} / \bar{P}$, where $\bar{e}=e_{0}$ and $\bar{P}=\left(\phi+p_{0}\right)+\left(p_{D}^{*} / k+p_{\Pi}^{*}\right) \bar{\Pi}$ are, respectively, the long-run stationary level of $e$ and $P$. Then,

$$
\bar{\varepsilon}=\frac{r \bar{\Pi}}{\bar{\Pi}+r k p_{n}}-r
$$

The information structure affects the long-run stationary level of risk premium only through the long-run level of price, $\bar{P}$. Given the values of the underlying state variables governing the stock's future cash flows, the price of the stock decreases as the fraction of uninformed investors increases (see Figure 1). The same result holds for the long-run level of the price. Therefore, we conclude that the risk premium on the stock increases with the fraction of uninformed investors. As shown in Figure $4, \bar{\varepsilon}$ is an increasing function of $\omega$.

This result is quite intuitive. As we discussed earlier, the risk premium only depends on the fundamental risk of the stock perceived by the investors. When the fraction of uninformed investors increases, the price contains less information about future dividend growth. This increases the perceived uncertainty about future cash flows by the uninformed investors, hence the risk of investing in the stock. In the equilibrium, a higher premium for the stock is required. It should be clear that this result is mainly driven by the imperfect information the market has about the fundamentals. The information asymmetry plays little role here.

Given that price volatility also increases with the fraction of uninformed investors, we may also want to look at the premium normalized by price volatility, $\bar{\varepsilon} / \operatorname{Var}[P]$, i.e. the premium per volatility. Different patterns can be obtained, depending on the parameter values. $\bar{\varepsilon} / \operatorname{Var}[P]$ either increases monotonically with $\omega$, or decreases with $\omega$ first and then increases.

From equation (4.7), the unconditional expected excess return from the stock is given by $e_{0}$. As discussed in Section 3, $e_{0}$ is independent of $\sigma_{\Theta}$ under perfect information $(\omega=0)$. Similarly, one can show that the same result holds when $\omega=1$, i.e. when all investors are uninformed. Hence, the variability of supply shocks does not affect the

34. See, for example, Mankiw and De Long (1989). 
$\bar{\varepsilon}$

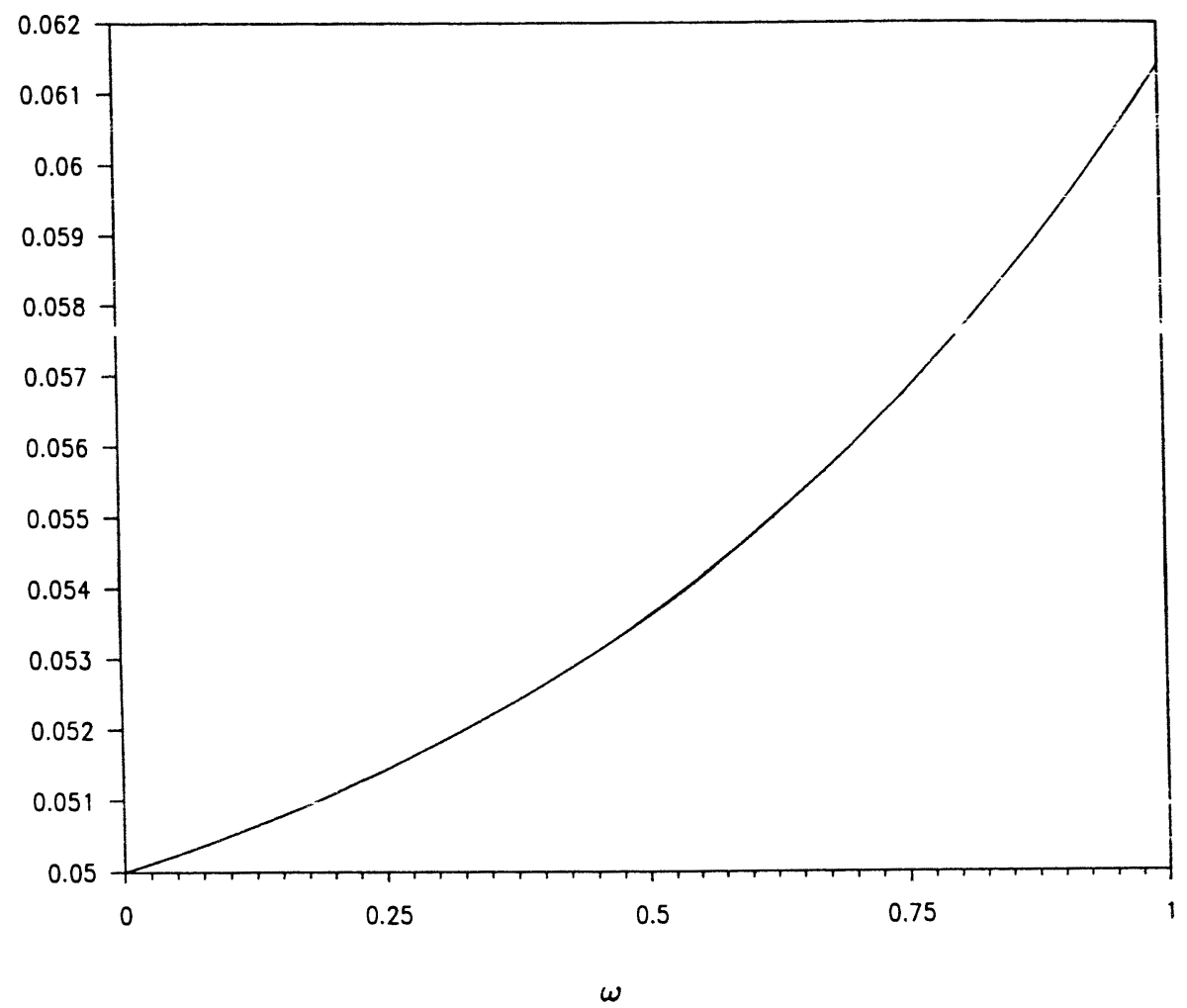

FIGURE 4

$\bar{\varepsilon}$ plotted against $\omega . \quad r=0 \cdot 05, \rho=0 \cdot 2, \bar{\Pi}=0 \cdot 8, k=1 \cdot 0, \sigma_{D}=1 \cdot 0, \sigma_{\Pi}=0 \cdot 6, \sigma_{\Theta}=3 \cdot 0, a_{\Pi}=0 \cdot 2, a_{\Theta}=0 \cdot 4$

unconditional expected excess return without information asymmetry. However, Figure 5 illustrates that when there is information asymmetry $\sigma_{\Theta}$ will affect the unconditional expected excess return. This is because under asymmetric information, less informed investors rely on prices and dividends to learn about the future dividend growth. As $\sigma_{\Theta}$ increases the uncertainty in future cash flows perceived by the uninformed investors increases. Consequently, they demand a higher return.

\subsection{Special correlation in stock returns}

Recent empirical studies (Fama and French (1987), Lo and Mackinlay (1988), Poterba and Summers (1988)) have found significant negative serial correlation in stock returns over long horizons of 3-5 years. Negative autocorrelation in returns suggests the existence of stationary components in stock prices (Summers (1986)). In this section, we employ our model to study the behaviour of stock returns. For convenience, we consider the returns to the zero-wealth portfolio defined in Section 4, or equivalently, the excess return to one share of stock.

Under asymmetric information, the return to the zero-wealth portfolio is derived in Theorem 4.2:

$$
d Q=\left[e_{0}+e_{\Theta} \Theta+e_{\Delta} \Delta\right] d t+\mathbf{b}_{P} d \underline{w} .
$$




\section{$\mathbf{E}[d Q] / d t$}

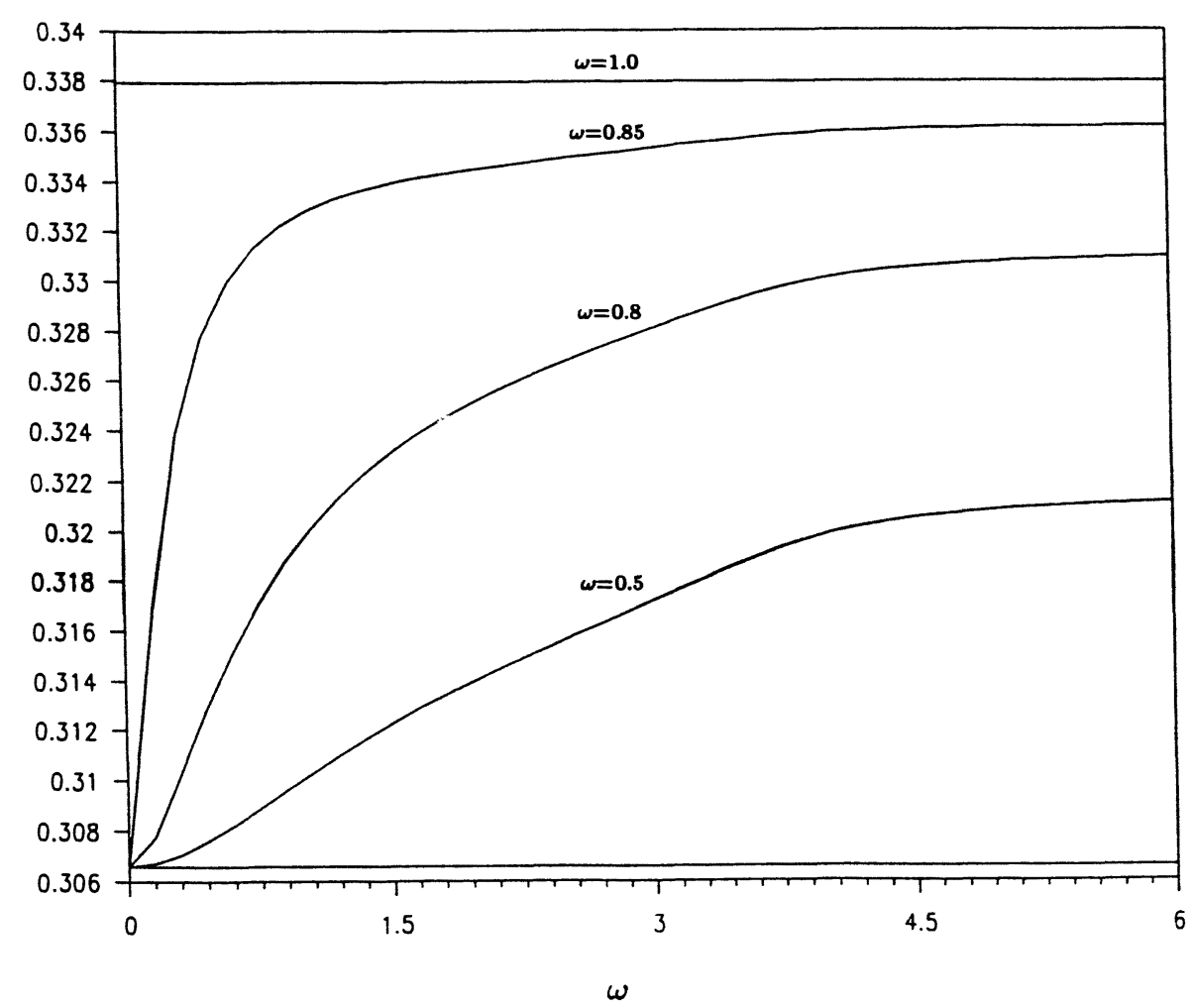

Figure 5

$\boldsymbol{E}[d Q] / d t$ plotted against $\sigma_{\Theta} \cdot r=0 \cdot 05, \rho=0 \cdot 2, \bar{\Pi}=0 \cdot 85, k=1 \cdot 0, \sigma_{D}=1 \cdot 0, \sigma_{\Pi}=0 \cdot 6, a_{\Pi}=0 \cdot 2, a_{\Theta}=0 \cdot 4$

Let $\gamma_{\Theta}=\left(1+r / a_{\Theta}\right) p_{\Theta}$, and $\gamma_{\Delta}=\left(1+r / a_{\Delta}\right) p_{\Delta} . Q$ has the following solution (see, e.g. Arnold (1974)):

$$
\begin{aligned}
Q(t)= & Q\left(t_{0}\right)+e_{0}\left(t-t_{0}\right)+\gamma_{\Theta}\left[\Theta(t)-\Theta\left(t_{0}\right)\right]+\gamma_{\Delta}\left[\Delta(t)-\Delta\left(t_{0}\right)\right] \\
& +\int_{t_{0}}^{t}\left(\mathbf{b}_{P}-\gamma_{\Theta} \mathbf{b}_{\Theta}-\gamma_{\Delta} \mathbf{b}_{\Delta}\right) d \underline{w}(s),
\end{aligned}
$$

In order to look at the serial correlation in stock returns, let us consider the following ratio:

$$
\beta(\tau)=\frac{\operatorname{Cov}[Q(t+\tau)-Q(t), Q(t)-Q(t-\tau)]}{\operatorname{Var}[Q(t)-Q(t-\tau)]} .
$$

$\beta(\tau)$ is calculated in Appendix C. The numerator in Equation (5.14) is the unconditional covariance between the returns from two consecutive holding periods of length $\tau$ :

$\operatorname{Cov}[Q(t+\tau)-Q(t), Q(t)-Q(t-\tau)]$

$$
=-\frac{1}{a_{\Theta}} p_{\Theta}^{2} \sigma_{\Theta}^{2}\left(1-\frac{r^{2}}{a_{\Theta}^{2}}\right) \times\left[\frac{1}{2}+\frac{a_{\Theta}}{a_{\Theta}+a_{\Delta}} p_{\Delta} h_{\Pi \Lambda}\right]\left[g\left(\tau, a_{\Theta}\right)\right]^{2},
$$


where $g(\tau, a)=1-e^{-a \tau}$. The covariance is negative if $r<a_{\Theta}$ and positive if $r>a_{\Theta}{ }^{35}$

Consider the case when $r<a_{\Theta}$, i.e. the covariance is negative. The strong meanreversion in $\Theta$ generates negative serial correlation in stock returns even under symmetric information. Under asymmetric information, however, the negative serial correlation can be enhanced by the information effect of dividends and prices on the behaviour of uninformed investors. Consider the simple case in which the current dividend turns out to be low (i.e. lower than expected), while $\Pi$ and $\Theta$ have remained the same. In the case of symmetric information, the drop in dividend gives a low return for the current period but has no effect on the future expected returns with $\Theta$ being constant. ${ }^{36}$ When there is information asymmetry, however, the low dividend causes the uninformed investors to decrease their estimate of $\Pi$ and $\Theta$ (see Theorem 4.1). The expected return on the stock will be low which causes them to sell their shares. The price drops more than in the case of symmetric information. As new information arrives, the uninformed investors update their expectations which leads to a correlation in price which gives rise to a reversal in

\section{$\beta(\tau)$}

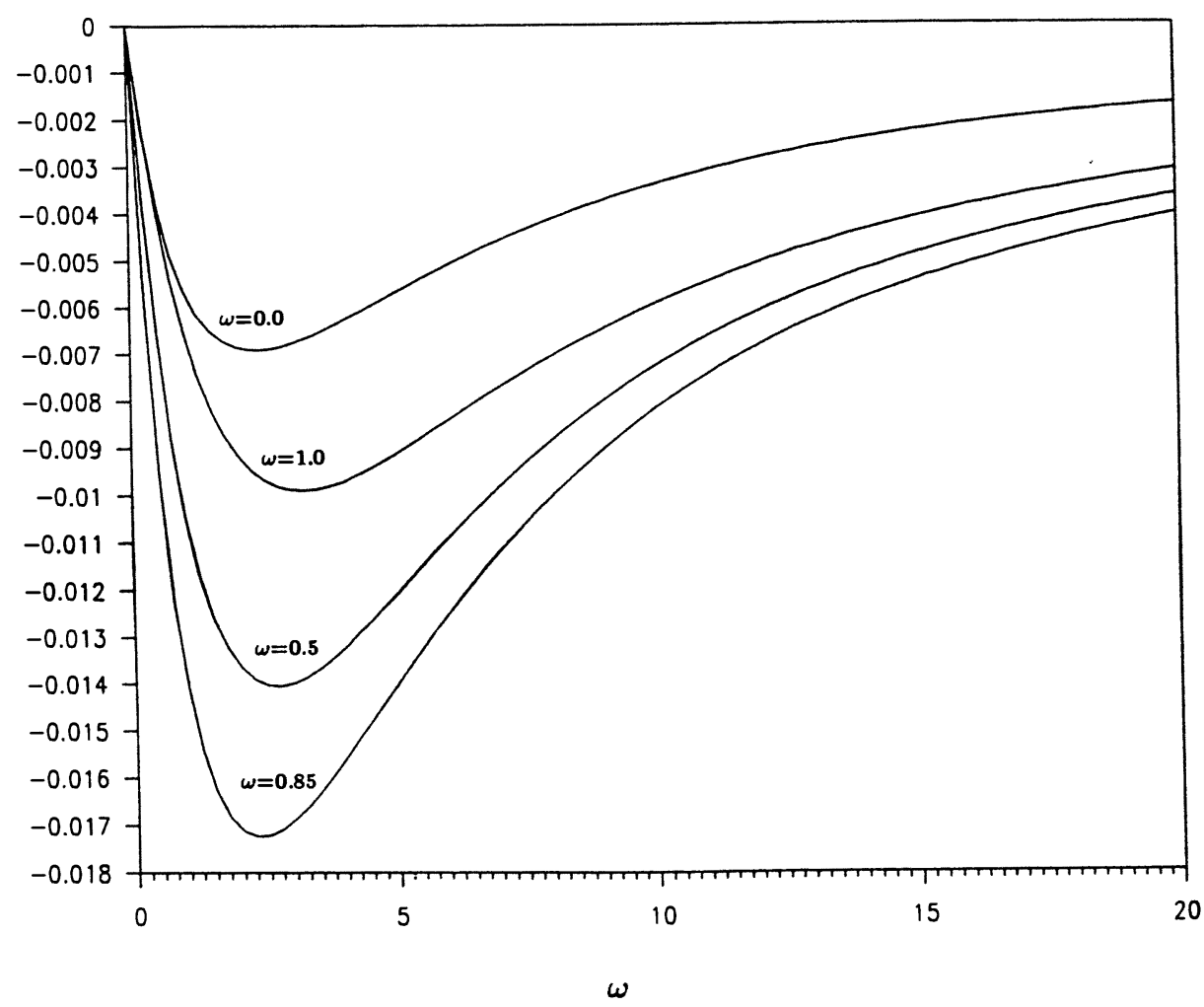

FIGURE 6

$\beta(\tau)$ plotted against $\tau . r=0.05, \rho=0 \cdot 2, \bar{\Pi}=0 \cdot 85, k=1 \cdot 0, \sigma_{D}=1 \cdot 0, \sigma_{\Pi}=0 \cdot 6, \sigma_{\Theta}=0 \cdot 8, a_{\Pi}=0 \cdot 2, a_{\Theta}=0.4$

35. When $r>a_{\Theta}$, fluctuations of $\Theta$ from its stationary level take long time to diminish. The return on the zero-wealth portfolio is dominated by its financing cost. This leads to a positive serial correlation.

36. Note that a change in the current dividend does affect the expected future cash flow of the stock. But this effect is fully incorporated into the current price. Hence, it has no effect on the expected future excess return under symmetric information. See also the discussion in Section 3. 
price changes. Figure 6 shows how information asymmetry can significantly enhance the negative serial correlation in returns. ${ }^{37}$

\section{OPTIMAL INVESTMENT STRATEGIES}

In this section, we examine the trading strategies of both the informed and the uninformed investors. We have seen in the previous sections that in equilibrium, investors with different information expect different returns from the stock. Hence, they follow different investment policies.

Given the equilibrium price, Theorem 4.3 gives the optimal stock holding of an informed investor:

$$
X^{i}=f_{0}^{i}+f_{\Theta}^{i} \Theta+f_{\Delta}^{i} \Delta .
$$

As shown in Section 4, the informed investors' expected excess return is determined by two factors: aggregate supply of the stock $\Theta$ and the uninformed investors' estimation error $\Delta$. Knowledge about expected future revisions in the uninformed investors' estimates does not provide the informed investors with arbitrage opportunities. However, the informed investors do take advantage of their superior information to make profits by positioning themselves against expected changes in $\Delta$. Due to risk-aversion, the informed investors will not take positions large enough to completely eliminate the price deviations caused by the uninformed investors.

The optimal investment policy of the uninformed investors is given by Theorem 4.4. We rewrite it as

$$
X^{u}=f_{0}^{u}+f_{\Theta}^{u} \Theta .
$$

$\hat{\Theta}$ is the only state variable that affects the excess return on the stock anticipated by an uninformed investor, hence the variable that determines his stock holding. $f_{\Theta}^{u}$ is positive. ${ }^{38}$ Intuitively, equation (6.2) states that the uninformed investors hold their optimal share of the market. They trade only when they perceive a change of the total market which is not directly observed. Their expectation of the market changes when new information arrives.

Consider now how an uninformed investor's demand for stock responds to changes in prices, which is characterized by the conditional covariance between $d X^{u}$ and $d P: \mathbf{E}\left[d X^{u} d P \mid \mathscr{F}^{u}\right]$. Given the demand schedule in equation (6.2),

$$
\mathbf{E}\left[d X^{u} d P \mid \mathscr{F}^{u}\right]=f_{\Theta}^{u} \mathbf{E}\left[d P d \hat{\Theta} \mid \mathscr{F}^{u}\right]=f_{\Theta}^{u} \sigma_{P \hat{\Theta}} .
$$

$f_{\Theta}^{u}$ is positive and the sign of $\mathbf{E}\left[d X^{u} d P \mid \mathscr{F}^{u}\right]$ is the same as that of $\left.\mathbf{E}[d P d \hat{\Theta}] \mid \mathscr{F}^{u}\right]$. As we show in Figure 7, E $\left[d P d \hat{\Theta} \mid \mathscr{F}^{u}\right]$ can be positive for certain parameters values. ${ }^{39}$ This sets forth the case where changes in the uninformed investors' stock holdings are positively correlated with changes in prices. They buy when the price goes up and sell when it goes

37. The result that information asymmetry can enhance serial correlation may be somewhat counterintuitive. One might argue that if there is serial correlation in returns, why do uninformed investors not take advantage of it by simply following contrarian strategies which would reduce the serial correlation? Such strategies cannot be optimal for uninformed investors due to the following reason. The uninformed investors know more than just returns. They know dividends and prices separately. Their optimal strategy is conditioned on both dividends and prices. It may not "look" optimal conditioned on a coarser information set such as past returns. Also see the discussion in the following section.

38. $f_{\Theta}^{u}>0$ supports the following intuition. When informed investors infer that $\Theta$ is high, their holding should also increase. Otherwise, it must be the informed investors who are holding more, which cannot be an equilibrium situation for the uninformed investors.

39. Figure 7 is not the dominating pattern observed in the parameter space. The situation that $\sigma_{P \hat{\Theta}}$ is always negative is often observed when we move in the parameter space, especially when $r$ is small. 


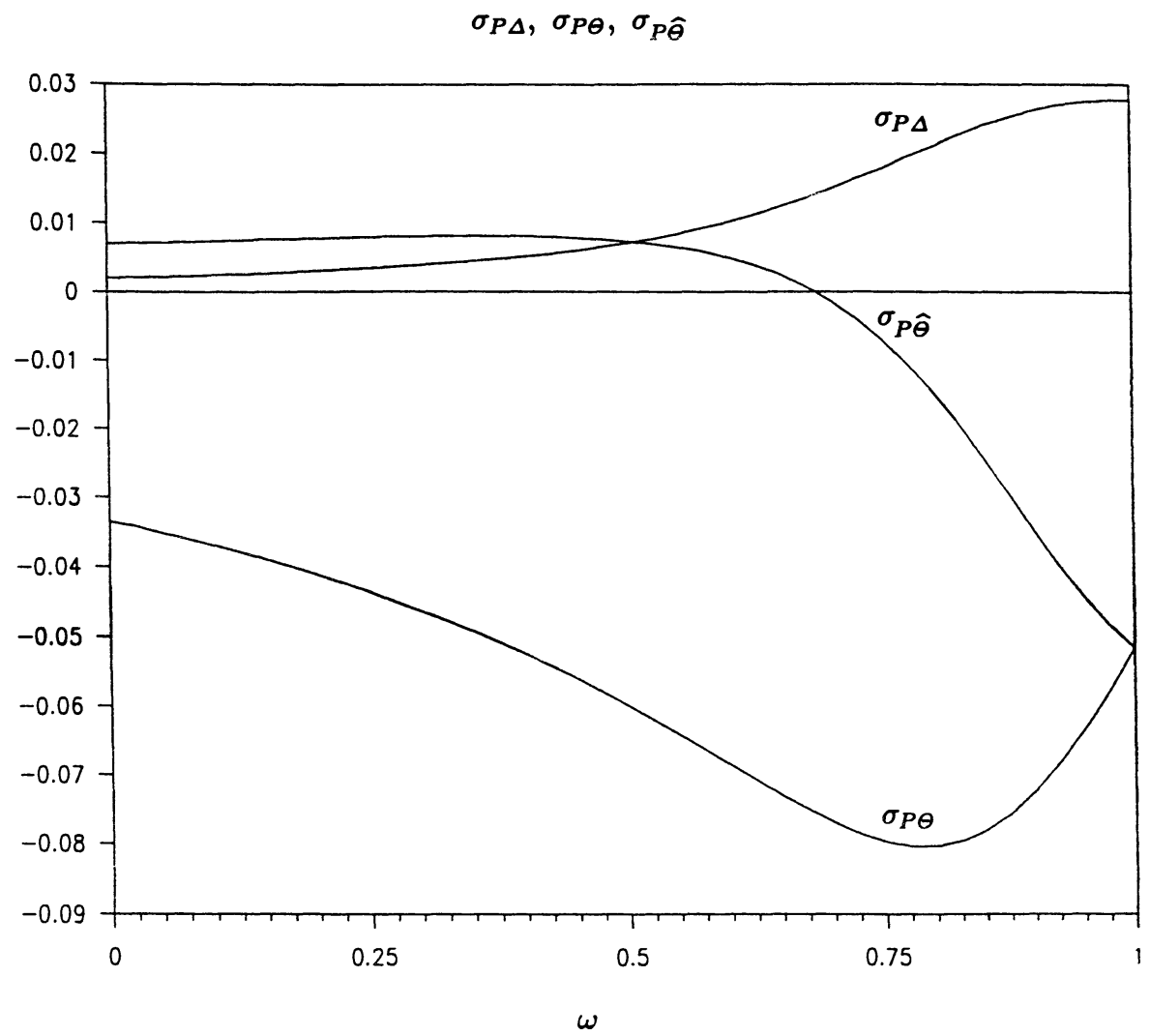

FIGURE 7

$\sigma_{P \Delta}, \sigma_{P \Theta}, \sigma_{P \Theta \hat{\Theta}}$ plotted against $\omega . \quad r=0 \cdot 8, \rho=0 \cdot 2, \bar{\Pi}=0 \cdot 85, k=1 \cdot 0, \sigma_{D}=0 \cdot 4, \sigma_{\Pi}=0 \cdot 1, \sigma_{\Theta}=1 \cdot 0, a_{\Pi}=0 \cdot 01$, $a_{\circledast}=0.5$

down. Figure 8 shows examples in which the uninformed investors behave as trend chasers while the informed investors act like contrarians.

In order to understand the trend-chasing-like behaviour, consider how unexpected price changes affect the uninformed investors' expectation about the aggregate supply (i.e. $\hat{\Theta}$ ) since they only trade when they perceive a change in the supply. Unexpected price changes are caused either by cash-flow related shocks (e.g. unexpected dividend changes) or by supply shocks. Under symmetric information $(\omega=1$ or $\omega=0)$, the equilibrium price fully reveals $\Theta$. Cash-flow related shocks like innovations in dividends have no impact on investors' expectation of the aggregate supply. Since price responds to supply shocks negatively $\left(p_{\Theta}^{* *}<0\right.$ in the case of $\left.\omega=1\right), \mathbf{E}\left[d X^{u} d P \mid \mathscr{F}^{u}\right]=f_{\Theta}^{u} p_{\Theta}^{* *} \sigma_{\Theta}^{2}<0$ Hence, investors behave like contrarians.

Under information asymmetry, however, price does not reveal the aggregate supply. Both type of shocks affect the uninformed investors' expectations of the aggregate supply but in very different directions. If an unexpected price increase is due to good news on cash flow such as an unexpectedly high dividend, the uninformed investors will infer that their previous estimate of $\Pi$ is too low and so is that of $\Theta .^{40}$ This implies that they have

40. Note that observing $\Lambda=p_{\Pi} \Pi+p_{\Theta} \Theta$, the uninformed investors know the weighted difference between $\Pi$ and $\Theta$ (since $p_{\Pi}>0$ and $\left.p_{\Theta}<0\right)$. Hence, if $\Pi$ is underestimated so is $\Pi$. 


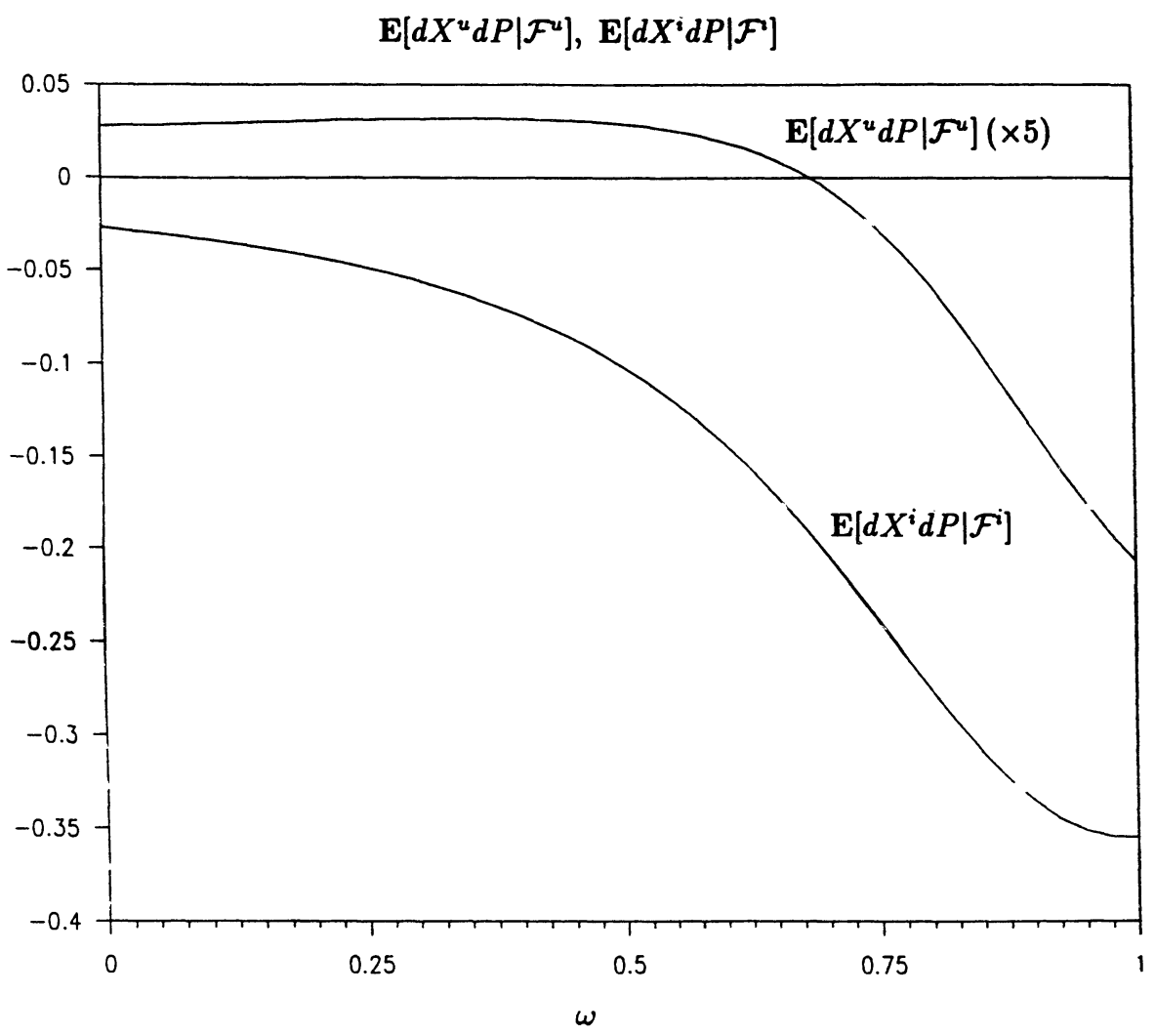

Figure 8

$\boldsymbol{E}\left[d X^{u} d P \mid \mathscr{F}^{u}\right], E\left[d X^{i} d P \mid \mathscr{F}^{i}\right]$ plotted against $\omega . r=0 \cdot 8, \rho=0 \cdot 2, \bar{\Pi}=0 \cdot 85, k=1 \cdot 0, \sigma_{D}=0 \cdot 4, \sigma_{\Pi}=0 \cdot 1, \sigma_{\Theta}=1 \cdot 0$, $a_{\Pi}=0.01, a_{\Theta}=0.5$

been holding less than the optimal share of the market since they have underestimated $\Theta$. Hence, they will update their expectation by increasing their estimate of the market, $\hat{\Theta}$, and buy more stock shares. ${ }^{41}$ If an unexpected price increase is not due to cash-flowrelated information, it must be due to a decrease of the aggregate supply (i.e. $\Theta$ ). In this case, the uninformed investors will lower $\hat{\Theta}$ and sell their shares accordingly.

Therefore, under information asymmetry the uninformed investors' reaction to an unexpected price increase is positive (to buy) if it is due to cash-flow related shocks and negative (to sell) if it is not. The overall response to price changes is the net of these two effects. As shown by Figure 8, for some parameter values the information effect of cash-flow-related shocks can dominate. In this case, $\sigma_{P \hat{\Theta}}>0$ and the uninformed investors buy the stock when the price rises and sell when the price drops. Clearly, the trend-chasing behaviour is associated with information asymmetry. This point becomes obvious as we compare with the limiting case of $\omega=1$ when all investors are uninformed and there is no information asymmetry.

Several empirical studies suggest that some investors in the market behave like price chasers: they buy when the price rises and sell when the price drops. ${ }^{42}$ We have just

41. The fact that $h_{D \Lambda}>0$ in the filtering equation proves the point that $d \hat{\Theta}$ is positively correlated with $d D$.

42. See the discussion in De Long et al. (1990) and the references therein. 
shown that trend-chasing can be the rational behaviour of less informed investors under asymmetric information in the current model.

\section{FURTHER DISCUSSIONS AND COMMENTS}

In the current model, we have assumed the aggregate stock supply to be stochastic. This is purely for simplicity in exposition as mentioned earlier. One can easily think of ways of introducing additional state variables instead of assuming stochastic supply. Wang (1990) develops a model with only rational investors, risky production and a constant stock supply. Most of the results are formally the same as here.

We have made many simplifying assumptions. Some of these assumptions can be relaxed quite easily.

For example, we can allow investors to have different degrees of risk aversion as long as they remain in the CARA class. The aggregation theorems (see e.g. Rubinstein (1974)) enable us to reduce the economy to an effective two-person setup as used in this paper. We should point out that the results in this paper depend on the assumption of risk-aversion among all investors. It is the risk aversion of the informed investors that prevents them from taking very large positions to take advantage of the uninformed investors' estimation errors. If the informed investors were risk neutral, the only equilibrium in the current competitive set-up would be a fully revealing one. It can be interesting to look at how the risk aversion of the two types of investors affect the results.

As for the information structure, one can assume that in addition to dividends and prices the uninformed investors receive other exogenous signals, which also have the same linearity as dividends. In addition, we may extend the model to include more than two classes of differently informed investors. When the information sets of different classes of investors have a complete ranking in terms of statistical dominance, the extension would be straightforward. However, if the ranking is not complete, the situation becomes more complicated.

We have modelled the information structure of the economy in a discrete fashion. There are a finite number of signals available to the investors (e.g. $D, P, \Pi, \Theta)$. An investor either does or does not have access to each signal. This may introduce certain instabilities into the equilibrium of the economy in terms of the information structure. To illustrate this, let us consider the case in which the population of informed investors is very small. The price contains certain information that only the informed investors have and hence provides a valuable source of information to the uninformed investors. This is true no matter how small the informed investors' population is as long as it is not exactly zero. The structure of the economy as well as the values of all the parameters are common knowledge. Even though the informed investors only have a very small impact on the price, the uninformed investors would have no trouble in identifying the exact perturbation on the price caused by the informed investors. ${ }^{43}$ The absolute magnitude of the signal has nothing to do with its information content. Hence, the uninformed investors can still extract the same amount of information from the price. However, when the population of the informed investors is exactly zero, the price does not convey any information held by the informed investors. Therefore, the information content may change abruptly when $\omega$ reaches 1 . This implies that the limiting equilibrium as $\omega \rightarrow 1$ can be very different from the equilibrium when $\omega=1$.

43. This is the result of the competitive assumption and may not be true if investors are allowed to behave strategically. 
In the current model, however, the instability suggested above is not present. The reason is that when $\omega=1$, price remains a valuable source of information to the uninformed investors because it fully reveals the supply of the stock. The information content is continuous in some sense as $\omega$ approaches 1 . But we have found examples of instabilities in a variant model in which prices become informationally valueless when $\omega$ is $1 .^{44}$ The existence of instabilities in the information structure becomes an important issue if we try to endogenize the information structure.

\section{CONCLUSION}

This paper presents an equilibrium model of asset pricing under asymmetric information. The model involves investors who are differently informed about the state of the economy. Investors rationally extract information from all the available signals including prices. They trade competitively in the market to maximize expected utility. We obtain a closed-form solution to the rational expectations equilibrium of the economy.

We employ the model to investigate the impact of asymmetric information on equilibrium asset prices, price variability, risk premia, serial correlation in returns and optimal trading strategies. We illustrate that the existence of investors with imperfect information increases the risk premia on stocks. Stock prices can become more variable when investors have less information about future cash flows. We also find that the informed investors can destabilize the price and information asymmetry can increase the price volatility and negative serial correlation in returns. Another implication of our model is that although supply shocks do make price more volatile, only under asymmetric information can the variability of supply shocks affect the unconditional expected excess return. It is also shown that under asymmetric information, investors with different information adopt different investment strategies. Less informed investors may rationally act like trend chasers.

In a separate paper (Wang (1991)), we use a variant form of the current model to study the behaviour of trading volume and its relation to price dynamics.

\section{APPENDIX A. SOLUTION TO THE UNINFORMED INVESTORS' FILTERING PROBLEM}

In this appendix, we solve the filtering problem of the uninformed investors. Our result is a special case of the iollowing Lemma. ${ }^{15}$

Lemma A.1. Suppose that

$$
\begin{aligned}
& d \underline{z}(t)=\left[a_{z 0}+a_{z z} \underline{z}(t)+a_{z s} \underline{s}(t)\right] d t+b_{z} d \underline{w}(t), \\
& d \underline{s}(t)=\left[a_{s 0}+a_{s z} \underline{z}(t)+a_{s s} \underline{s}(t)\right] d t+b_{s} d \underline{w}(t),
\end{aligned}
$$

where $\underline{z}(t)$ is an $n$-vector of state variables, $\underline{s}(t)$ is an m-vector of signals, $\underline{w}(t)$ is a $k$-vector standard Wiener process, $\boldsymbol{a}_{z 0}, \boldsymbol{a}_{s 0}, \boldsymbol{a}_{z z}, \boldsymbol{a}_{s z}, \boldsymbol{a}_{z s}, \boldsymbol{a}_{s s}, \boldsymbol{b}_{z}$ and $\boldsymbol{b}_{s}$ are respectively $(n \times 1),(m \times 1),(n \times n),(m \times n),(n \times m),(m \times m)$, $(n \times k)$ and $(m \times k)$ matrices of constants. Let $\boldsymbol{q}_{z z}=\boldsymbol{b}_{z} \boldsymbol{b}_{z}^{T}, \boldsymbol{q}_{s s}=\boldsymbol{b}_{s} \boldsymbol{b}_{s}^{T}$ and $\boldsymbol{q}_{z s}=\boldsymbol{b}_{z} \boldsymbol{b}_{s}^{T}$. Suppose that the prior is $\underline{z}\left(t_{0}\right) \sim \mathcal{N}\left(\underline{z}_{0}, o_{0}\right)$. Conditioned on the observations of $\underline{\underline{s}}(t)$, the posterior mean of $\underline{\underline{z}}(t)$, i.e. the filter $\underline{\hat{\hat{n}}}(t) \equiv \boldsymbol{E}\left[\underline{z} \mid \mathscr{F}_{t}^{u}\right]$, is given by the stochastic differential equation:

$$
d \hat{z}(t)=\left[a_{z 0}+a_{z z} \hat{z}(t)+a_{z s} \underline{s}(t)\right] d t+\left[o(t) \boldsymbol{a}_{z z}^{T}+\boldsymbol{q}_{z s}\right] \boldsymbol{q}_{s s}^{-1} d \underline{\tilde{w}}(t) .
$$

Here $\boldsymbol{o}(t)=\boldsymbol{E}\left[(\underline{\hat{z}}-\underline{z})(\underline{\hat{z}}-\underline{z})^{T}\right]$ is a positive definite symmetric matrix given by the solution to the Riccati equation:

$$
\dot{\boldsymbol{o}}(t)=\boldsymbol{a}_{z z} \boldsymbol{o}(t)+\boldsymbol{o}(t) \boldsymbol{a}_{z z}^{T}+\boldsymbol{q}_{z z}-\left[\boldsymbol{o}(t) \boldsymbol{a}_{s z}^{T}+\boldsymbol{q}_{z s}\right] \boldsymbol{q}_{s s}^{-1}\left[\boldsymbol{b}_{s z} \boldsymbol{o}(t)+\boldsymbol{q}_{z s}^{T}\right] .
$$

44. In Wang (1990), hedging against changes in private investment opportunities plays the role of supply shocks. One can show that there exists a disruptive change in equilibrium as $\omega$ approaches 1.

45. For a complete treatment of the filtering problem, see Liptser and Shiryayev (1977). 
The innovation process, $\tilde{\tilde{w}}(t)$, defined by

$$
d \underline{\tilde{w}}(t)=d \underline{s}(t)-\left[a_{s 0}+a_{s z} \hat{z}(t)-a_{s s} \underline{s}(t)\right] d t
$$

is a Wiener process with respect to $\mathscr{F}^{s}(t)$.

In the filtering problem of the uninformed investors, the signals are $D$ and $\Lambda$, where $\Lambda=p_{\Pi} \Pi+p_{\Theta} \Theta . \Lambda$ follows the process:

$$
d \Lambda=\left[a_{\Pi} p_{\Pi}(\bar{\Pi}-\Pi)-a_{\Theta} p_{\Theta} \Theta\right] d t+b_{\Lambda} d \underline{w},
$$

where $b_{\Lambda}=\left(0, p_{\Pi} \sigma_{\Pi}, p_{\Theta} \sigma_{\Theta}\right)$ and $\sigma_{\Lambda}^{2}=b_{\Lambda} b_{\Lambda}^{T}$. Let $\underline{s}^{T}(t)=[D(t), \Lambda(t)]$ be the vector of signals, $\underline{z}^{T}(t)=[\Pi(t), \Theta(t)]$ the vector of state variables and $\underline{w}^{T}(t)=\left[w_{D}(t), w_{\Pi}(t), w_{\Theta}(t)\right]$. Define the parameter matrices accordingly:

$$
\begin{array}{ll}
\boldsymbol{a}_{z 0}=\left(\begin{array}{c}
a_{\Pi} \bar{\Pi} \\
0
\end{array}\right), & \boldsymbol{a}_{z z}=\left(\begin{array}{cc}
-a_{\Pi} & 0 \\
0 & -a_{\Theta}
\end{array}\right), \quad \boldsymbol{a}_{z s}=0, \quad \boldsymbol{b}_{z}=\left(\begin{array}{l}
\boldsymbol{b}_{\Pi} \\
\boldsymbol{b}_{\Theta}
\end{array}\right), \\
\boldsymbol{a}_{s 0}=\left(\begin{array}{c}
0 \\
a_{\Pi} p_{\Pi} \bar{\Pi}
\end{array}\right), & \boldsymbol{a}_{s z}=\left(\begin{array}{cc}
1 & 0 \\
-a_{\Pi} p_{\Pi} & -a_{\Theta} p_{\Theta}
\end{array}\right), \quad \boldsymbol{a}_{s s}=0, \quad \boldsymbol{b}_{s}=\left(\begin{array}{l}
\boldsymbol{b}_{D} \\
\boldsymbol{b}_{\Lambda}
\end{array}\right) .
\end{array}
$$

Applying Lemma A.1 by substituting the parameter matrices into equation (A.3) and (A.4), we obtain the equations for the filters of the uninformed investors.

In this paper we are only interested in the steady-state solution of the economy. ${ }^{46}$ We look for the steady-state solution to the Riccati equation, denote by

$$
o_{\infty}=\left(\begin{array}{ll}
o_{11} & o_{12} \\
o_{12} & o_{22}
\end{array}\right)
$$

$\boldsymbol{o}_{\infty}$ satisfies the following equation:

$$
\boldsymbol{a}_{z z} \boldsymbol{o}_{\infty}+\boldsymbol{o}_{\infty} \boldsymbol{a}_{z z}^{T}+\boldsymbol{q}_{z z}-\boldsymbol{h} \boldsymbol{q}_{s s} \boldsymbol{h}^{T}=0
$$

where

$$
\boldsymbol{h}=\left(\boldsymbol{o}_{\infty} \boldsymbol{a}_{s z}^{T}+\boldsymbol{q}_{z s}\right) \boldsymbol{q}_{s s}^{-1} \equiv\left(\begin{array}{ll}
h_{\Pi D} & h_{\Pi \Lambda} \\
h_{\Theta D} & h_{\Theta \Lambda}
\end{array}\right) .
$$

From Lemma 4.1 in Section 4, $p_{\Pi}(\Pi-\hat{\Pi})=-{ }_{\Theta}(\Theta-\hat{\Theta})$. This leads to the following steady state solution of the Riccati equation:

$$
\begin{gathered}
o_{11}=\frac{\sigma_{D}^{2}}{\sigma_{\Lambda}^{2}+\left(a_{\Pi}-a_{\Theta}\right)^{2} p_{\Pi}^{2} \sigma_{D}^{2}}\left[-\left(a_{\Pi} p_{\Theta}^{2} \sigma_{\Theta}^{2}+a_{\Theta} p_{\Pi}^{2} \sigma_{\Pi}^{2}\right)+\sigma_{\Lambda} \sqrt{\left(a_{\Pi}^{2} p_{\Theta}^{2} \sigma_{\Theta}^{2}+a_{\Theta}^{2} p_{\Pi}^{2} \sigma_{\Pi}^{2}\right)+p_{\Theta}^{2} \sigma_{\Pi}^{2} \sigma_{\Theta}^{2} / \sigma_{D}^{2}}\right], \\
o_{12}=-\frac{p_{\Pi}}{p_{\Theta}} o_{11}, \quad o_{22}=\frac{p_{\Pi}^{2}}{p_{\Theta}^{2}} o_{11} .
\end{gathered}
$$

The filters are expressed as

$$
\begin{aligned}
{\left[\begin{array}{c}
d \hat{\Pi} \\
d \hat{\Theta}
\end{array}\right] } & =\left[\begin{array}{c}
a_{\Pi}(\bar{\Pi}-\hat{\Pi}) \\
-a_{\Theta} \hat{\Theta}
\end{array}\right] d t+\left[\begin{array}{ll}
h_{\Pi D} & h_{\Pi \Lambda} \\
h_{\Theta D} & h_{\Theta \Lambda}
\end{array}\right]\left(b_{s} b_{s}^{T}\right)^{1 / 2} d \underline{w}, \\
d \underline{w} & \equiv\left(b_{s} b_{s}^{T}\right)^{-1 / 2}\left[\begin{array}{c}
d D-a_{D}(\hat{\Pi}-k D) d t \\
d \Lambda-a_{\Pi} p_{\Pi(}(\bar{\Pi}-\hat{\Pi}) d t+a_{\Theta} p_{\Theta} \hat{\Theta} d t
\end{array}\right] .
\end{aligned}
$$

Let $\boldsymbol{b}_{\hat{\Pi}}=\left(h_{\Pi D} \sigma_{D}, h_{\Pi \Lambda} p_{\Pi} \sigma_{\Pi}, h_{\Pi \Lambda} p_{\Theta} \sigma_{\Theta}\right), b_{\hat{\Theta}}=\left(h_{\Theta D} \alpha_{D}, g_{\Lambda \Lambda} p_{\Pi} \alpha_{\Pi}, h_{\Theta \Lambda} p_{\Theta} \sigma_{\Theta}\right)$. Then, $\sigma_{\hat{\Pi}}^{2}=b_{\hat{\Pi}} b_{\hat{\Pi}}^{T}$ and $\sigma_{\hat{\Theta}}^{2}=\boldsymbol{b}_{\hat{\Theta}} \boldsymbol{b}_{\hat{\Theta}}^{T}$. Let $\Delta=\hat{\Pi}-\Pi$. $\Delta$ follows an O-U process:

$$
d \Delta=-a_{\Delta} \Delta d t+b_{\Delta} d \underline{w}
$$

where $a_{\Delta}=a_{\Pi}+h_{\Pi D}+\left(a_{\Theta}-a_{\Pi}\right) p_{\Pi} h_{\Pi \Lambda}$ and $b_{\Delta}=b_{\hat{\Pi}}-b_{\Pi}$. It can be shown that $a_{\Delta}>0$.

Define $b_{P}=p_{D}^{*} b_{D}+p_{\Pi}^{*} b_{\Pi}+p_{\Theta} b_{\Theta}+p_{\Delta} b_{\Delta}$. Then, from the Proposition in Section 4 the price follows the process:

$$
d P=\left[p_{D}^{*}(\Pi-k D)+a_{\Pi} p_{\Pi}^{*}(\bar{\Pi}-\Pi)-a_{\Theta} p_{\Theta} \Theta-a_{\Delta} p_{\Delta} \Delta\right] d t+b_{P} d \underline{w} .
$$

The excess return on one share of stock is given by

$$
d Q=\left[e_{0}+e_{\Theta} \Theta+e_{\Delta} \Delta\right] d t+b_{P} d \underline{w}
$$

where $e_{0}=-r p_{0}, e_{\Theta}=-\left(r+a_{\Theta}\right) p_{\Theta}$ and $e_{\Delta}=-\left(r+a_{\Delta}\right) p_{\Delta}$.

Equation (A.14) completes the proof of Theorem 4.1 and 4.2. In the remaining part of this sub-section, we define some notation for future use.

46. Since our initial point is $-\infty$, the convergence of the filters to their steady state solution is guaranteed under mild conditions. See, for example, Anderson and Moore (1979). 
Let $\Psi^{i T}=(1, \Theta, \Delta)$ and $e_{Q}^{i}=\left(e_{0}, e_{\Theta}, e_{\Delta}\right)$. Then, $\underline{\Psi}^{i}$ is the variable that determines the informed investors' expected excess return on the stock: $E\left[d Q \mid \mathscr{F}^{i}\right]=\boldsymbol{e}_{Q}^{i} \underline{\Psi}^{i} d t . \underline{\Psi}^{i}$ is governed by the following linear process:

$$
d \underline{\Psi}^{i}=\boldsymbol{a}_{\Psi}^{i} \underline{\Psi}^{i} d t+\boldsymbol{b}_{\Psi}^{i} d \underline{w} \quad \text { where } \mathbf{a}_{\Psi}^{i}=\left(\begin{array}{ccc}
0 & 0 & 0 \\
0 & -a_{\Theta} & 0 \\
0 & 0 & -a_{\Delta}
\end{array}\right), \quad \boldsymbol{b}_{\Psi}^{i}=\left(\begin{array}{c}
0 \\
\boldsymbol{b}_{\Theta} \\
\boldsymbol{b}_{\Delta}
\end{array}\right) .
$$

Also define $\Psi^{u T}=(1, \hat{\Theta})$. The uninformed investors' expected excess return on the stock can then be expressed as $E\left[d Q \mid \mathscr{F}^{u}(t)\right]=e_{Q}^{u} \underline{\Psi}^{u} d t$, where $e_{Q}^{u}=\left(e_{0}, e_{\Theta}\right) . \underline{\Psi}^{u}$ is governed by the process:

$$
d \underline{\Psi}^{u}=a_{\Psi}^{u} \underline{\Psi}^{u} d t+b_{\Psi}^{u} d \tilde{w} \quad \text { where } \mathbf{a}_{\Psi}^{u}=\left(\begin{array}{cc}
0 & 0 \\
0 & -a_{\Theta}
\end{array}\right), \quad b_{\Psi}^{u}=\left(\begin{array}{cc}
0 & 0 \\
h_{\Theta D} & h_{\Theta \Lambda}
\end{array}\right) .
$$

We can re-express the excess return in terms of $\underline{\Psi}^{i}$ and $\underline{\Psi}^{u}$ :

$$
\begin{aligned}
d Q & =\boldsymbol{e}_{Q}^{i} \underline{\Psi}^{i} d t+\boldsymbol{b}_{Q}^{i} d \underline{w} \\
& =\boldsymbol{e}_{Q}^{u} \underline{\Psi}^{u} d t+\boldsymbol{b}_{Q}^{u} d \underline{\underline{w}}
\end{aligned}
$$

where $b_{Q}^{i}=b_{P}$ and $b_{Q}^{u}=\left(p_{D}^{*}+p_{\Delta} h_{\Pi D}, 1+p_{\Delta} h_{\Pi \Lambda}\right)$.

Let $x_{k}, k=1,2$, be any two variables such that $d x_{k}=E\left[d x_{k} \mid \mathscr{F}^{i}\right] d t+\boldsymbol{b}_{x_{k}} d \underline{w}$. The conditional convariance $\boldsymbol{E}\left[d x_{1} d x_{2} \mid \mathscr{F}^{i}\right] \equiv \sigma_{x_{1} x_{2}}$ can be easily calculated: $\sigma_{x_{1} x_{2}}=\boldsymbol{b}_{x_{1}} \boldsymbol{b}_{x_{2}}^{T}$. For example, $\sigma_{\Pi \hat{\Theta}}=\boldsymbol{b}_{\Pi} \boldsymbol{b}_{\Theta}^{T}, \sigma_{P \hat{\Theta}}=\boldsymbol{b}_{P} \boldsymbol{b}_{\Theta}^{T}$. If $x_{k}, k=$ 1,2 , is also $\mathscr{F}^{u}$-measurable, then $\boldsymbol{E}\left[d x_{1} d x_{2} \mid \mathscr{F}^{i}\right]=\boldsymbol{E}\left[d x_{1} d x_{2} \mid \mathscr{F}^{u}\right]$.

\section{APPENDIX B. SOLUTION TO INVESTORS' OPTIMIZATION PROBLEM}

In this appendix, we solve the optimal investment and consumption problem of the informed and uninformed investors respectively.

\section{B.1. Optimization problem of the informed investors}

The informed investor's optimization problem is stated by equation (4.9) in Section 4. Using the notation developed in Appendix A, we rewrite the Bellman equation in the following form:

$$
\begin{aligned}
0= & \operatorname{Max}_{c^{\prime}, X^{\prime}}\left[-e^{-\rho t-c^{t}}+J_{W}^{i}\left(r W^{i}-c^{i}+X^{i} e_{Q}^{i} \Psi^{i}\right)+\frac{1}{2} b_{Q}^{i} b_{Q}^{i T} X^{i 2} J_{W W}^{i}+X^{i} b_{Q}^{i} b_{\Psi}^{i T} J_{W \Psi}^{i}\right] \\
& -\rho J^{i}+\left(a_{\Psi}^{i} \underline{\Psi}^{t}\right)^{T} J_{\Psi}^{i}+\frac{1}{2} b_{\Psi}^{i} J_{\Psi \Psi}^{i} b_{\Psi}^{i T} .
\end{aligned}
$$

Here, we have used the notation:

$$
J_{\Psi}^{i}=\left(\frac{\partial J^{i}}{\partial \Psi_{1}^{i}}, \frac{\partial J^{i}}{\partial \Psi_{2}^{i}}, \frac{\partial J^{i}}{\partial \Psi_{3}^{i}}\right)^{T} \text { and } J_{\Psi \Psi}^{i}=\left\{\frac{\partial^{2} J^{i}}{\partial \Psi_{k} \partial \Psi_{k^{\prime}}}\right\} .
$$

Assume that the value function has the following form:

$$
J^{i}\left(W^{i} ; \Theta, \Delta ; t\right)=-e^{-\rho t-r W^{i}-\frac{1}{2} \underline{\Psi}^{i T} v^{t} \underline{\Psi}^{i}},
$$

where $v^{i}$ is a $(3 \times 3)$ symmetric matrix. The first-order conditions of the optimization problem leads to the optimal consumption and investment policies:

$$
c^{i}=r W^{i}+\frac{1}{2} \underline{\Psi}^{i T} v^{i} \underline{\Psi}^{i}-\ln (r), \quad X^{i}=\boldsymbol{f}^{i} \underline{\Psi}^{i},
$$

where $f^{i}=\left(r b_{Q}^{i T} b_{Q}^{i}\right)^{-1}\left(e_{Q}^{i}-b_{Q}^{i} b_{\Psi}^{i T} v^{i}\right){ }^{47}$ Substitute the optimal policies into the Bellman equation, we obtain the following equation for $v^{i}$ :

$$
\begin{aligned}
0= & v^{i} b_{\Psi}^{i} b_{\Psi}^{i} v^{i}-\left(b_{Q}^{i} b_{Q}^{i T}\right)^{-1}\left(e_{Q}^{i}-b_{Q}^{i} b_{\Psi}^{i T} v^{i}\right)^{T}\left(e_{Q}^{i}-b_{Q}^{i} b_{\Psi}^{i T} v^{i}\right) \\
& +r v^{i}-\left(a_{\Psi}^{i} v^{i}+v^{i} a_{\Psi}^{i}\right)+2 \kappa^{i} m_{11}^{(3)}
\end{aligned}
$$

47. The second-order condition for optimality is $b_{Q}^{i T} b_{Q}^{i} J_{W W}^{i}<0$, which is satisfied given the form of the value function. 
Here, $\kappa^{i}=[(r-\rho)-r \ln (r)]-\operatorname{Tr}\left(b_{\Psi}^{i T} b_{\Psi}^{i} v^{i}\right) . m_{k k^{\prime}}^{(n)}$ is the $(n \times n)$ index matrix which has all its elements being 0 except element $\left\{k k^{\prime}\right\}$ being 1. Equation (B.4) is a set of quadratic equations to which a solution exists. ${ }^{48}$

It can be shown that $E\left[d J^{i}\left(W^{i} ; \underline{\Psi}^{i} ; t\right) \mid \mathscr{F}^{i}\left(t_{0}\right)\right]=-r E\left[J^{i}\left(W^{i} ; \underline{\Psi}^{i} ; t\right) \mid \mathscr{F}^{i}\left(t_{0}\right)\right] d t\left(t>t_{0}\right)$. Then, $\lim _{t \rightarrow \infty} E\left[J^{i}\left(W^{i} ; \underline{\Psi}^{i} ; t\right) \mid \mathscr{F}^{i}\left(t_{0}\right)\right]=0$. Hence, the above solution satisfies the given transversality condition when $r>0$.

\section{B.2. Optimization problem of the uninformed investors}

The uninformed investor's optimization problem is stated by equation (4.13). As discussed in Appendix A, the information structure generated by $\mathscr{F}^{D, P}(t)$ iis equivalent to that generated by the innovation process $\tilde{\tilde{w}}$. Since $\underline{\tilde{w}}$ is a Wiener process with respect to $\mathscr{F}^{u}(t)$, the system $(\hat{\Pi}, \hat{\Theta})$ is a Gaussian Markov with respect to $\mathscr{F}^{u}$ (or $\left.\mathscr{F}^{\tilde{w}}\right)$. The uninformed investors' conditional distribution of the state variables is fully characterized by $(\hat{\Pi}, \hat{\Theta})$ with innovations generated by $\tilde{w}$. Using the $\tilde{w}$-representation of the information structure, the optimization problem of the uninformed investors becomes a Markovian one. Formally, it is similar to that of the informed investors except that filters are the effective state variables. This is an application of the Separation Principle in solving optimal control problems with partially observed state variables. ${ }^{49}$

Employing the notation defined in Appendix A, we rewrite the Bellman equation as follows:

$$
\begin{aligned}
0= & \operatorname{Max}_{c^{u}, X^{u}}\left[-e^{-\rho t-c^{u}}+J_{W}^{u}\left(r W^{u}-c^{u}+X^{u} e_{Q}^{u} \underline{\Psi}^{u}\right)+\frac{1}{2} b_{Q}^{u} b_{Q}^{u T} X^{u 2} J_{W W}^{u}+X^{u} b_{Q}^{u} b_{\Psi}^{u T} J_{W \Psi}^{u}\right] \\
& -\rho J^{u}+\left(a_{\Psi}^{u} \underline{\Psi}^{u}\right)^{T} J_{\Psi}^{u}+\frac{1}{2} b_{\Psi}^{u} J_{\Psi \Psi}^{u} b_{\Psi}^{u T} .
\end{aligned}
$$

Assume the value function to have the following form:

$$
J^{u}\left(W^{u} ; \hat{\Theta} ; t\right)=-e^{-\rho t-r W^{u}-\frac{1}{2} \underline{\Psi}^{u T} v^{u} \underline{\Psi}^{u}},
$$

where $v^{u}$ is a $(2 \times 2)$ symmetric matrix. The first-order conditions of the optimization problem gives the optimal consumption and investment policies:

$$
c^{u}=r W^{u}+\frac{1}{2} \underline{\Psi}^{u T} v^{u} \underline{\Psi}^{u}-\ln (r), \quad X^{u}=f^{u} \underline{\Psi}^{u},
$$

where $f^{u}=\left(r b_{Q}^{u T} b_{Q}^{u}\right)^{-1}\left(e_{Q}^{u}-b_{Q}^{u} b_{\Psi}^{u T} v^{u}\right)$. Substitute the optimal policies into the Bellman equation, we obtain the following equation for $v^{u}$ :

$$
\begin{aligned}
0= & \boldsymbol{v}^{u} \boldsymbol{b}_{\Psi}^{u} b_{\Psi}^{u T} \boldsymbol{v}^{u}-\left(\boldsymbol{b}_{Q}^{u} b_{Q}^{u T}\right)^{-1}\left(\boldsymbol{e}_{Q}^{u}-\boldsymbol{b}_{Q}^{u} b_{\Psi}^{u T} \boldsymbol{v}^{u}\right)^{T}\left(e_{Q}^{u}-b_{Q}^{u} b_{\Psi}^{u T} v^{u}\right) \\
& +r v^{u}-\left(a_{\Psi}^{u} v^{u} v^{u}+a_{\Psi}^{u}\right)+2 \kappa^{u} \boldsymbol{m}_{11}^{(2)}
\end{aligned}
$$

where $\kappa^{u}=[(r-\rho)-r \ln (r)]-\operatorname{Tr}\left(b_{\Psi}^{u T} b_{\Psi}^{u} v^{u}\right)$. It is easy to show that a solution exists for $v^{u} .^{50}$

\section{APPENDIX C. SOME MOMENTS OF RETURNS AND PRICES}

In this appendix, we calculate the serial correlation in excess returns and the unconditional variance of stock price.

Let

$$
\gamma_{\Theta}=-e_{\Theta} / a_{\Theta}, \gamma_{\Delta}=-e_{\Delta} / a_{\Delta}, d \underline{Y}=\left(\begin{array}{l}
d \tilde{Q} \\
d \Theta \\
d \Delta
\end{array}\right), \quad a_{\Upsilon}=\left(\begin{array}{ccc}
0 & e_{\Theta} & e_{\Delta} \\
0 & -a_{\Theta} & 0 \\
0 & 0 & -a_{\Delta}
\end{array}\right), \quad \boldsymbol{b}_{\mathbf{Y}}=\left(\begin{array}{l}
\boldsymbol{b}_{P} \\
\boldsymbol{b}_{\Theta} \\
\boldsymbol{b}_{\Delta}
\end{array}\right),
$$

where $d \tilde{Q}=d Q-e_{0} d t$ is the abnormal excess return on one share of stock. Then, $\underline{\Upsilon}$ satisfies the stochastic differential equation:

$$
d \underline{\Upsilon}=a_{\Upsilon} \underline{Y} d t+b_{Y} d \underline{w}
$$

48. The proof is available from the author upon request.

49. For a more detailed discussion of the Separation Principle, see Fleming and Rishel (1975), Whittle (1981), Bensoussan and van Schuppen (1985). See also Dothan and Feldman (1986), Detemple (1986), Gennotte (1986).

50. The solution satisfies the transversality condition. See the discussion for the case of the informed investors. 
Equation (C.1) has the solution (see, e.g. Arnold (1974)):

$$
\underline{Y}(t)=e^{a_{Y}\left(t-t_{0}\right)} \underline{Y}\left(t_{0}\right)+\int_{t_{0}}^{t} e^{a_{Y}(t-\tau)} b_{Y} d \underline{w}(\tau) .
$$

Explicitly, we have

$$
\begin{aligned}
& \Theta(t)=\Theta\left(t_{0}\right) e^{-a_{\Theta}\left(t-t_{0}\right)}+\int_{t_{0}}^{t} e^{-a_{\Theta}(t-\tau)} b_{\Theta} d \underline{w}(\tau), \\
& \Delta(t)=\Delta\left(t_{0}\right) e^{-a_{\Delta}\left(t-t_{0}\right)}+\int_{t_{0}}^{t} e^{-a_{\Delta}(t-\tau)} b_{\Delta} d \underline{w}(\tau), \\
& \tilde{Q}(t)=\tilde{Q}\left(t_{0}\right)+\gamma_{\Theta}\left[\Theta(t)-\Theta\left(t_{0}\right)\right]+\gamma_{\Delta}\left[\Delta(t)-\Delta\left(t_{0}\right)\right]+\int_{t_{0}}\left(b_{P}-\gamma_{\Theta} b_{\Theta}-\gamma_{\Delta} b_{\Delta}\right) d \underline{w}(\tau) .
\end{aligned}
$$

Let $g(\tau, a)=1-e^{-a \tau}, \gamma_{P \Theta}=\gamma_{\Theta} \sigma_{P \Theta}, \gamma_{P \Delta}=\gamma_{\Delta} \sigma_{P \Delta}, \gamma_{\Theta \Theta}=\gamma_{\Theta}^{2} \sigma_{\Theta}^{2}, \gamma_{\Delta \Delta}=\gamma_{\Delta}^{2} \sigma_{\Delta}^{2}, \gamma_{\Theta \Delta}=\gamma_{\Theta} \gamma_{\Delta} \sigma_{\Theta \Delta}$. Then,

$$
\begin{aligned}
\operatorname{Var}\left[Q(t+\tau)-Q(t) \mid \mathscr{F}^{i}(t)\right]= & \left(\sigma_{P}^{2}+\gamma_{\Theta \Theta}+\gamma_{\Delta \Delta}-2 \gamma_{P \Theta}-2 \gamma_{P \Delta}+2 \gamma_{\Theta \Delta}\right) \tau-\frac{2}{a_{\Theta}}\left(\gamma_{\Theta \Theta}-\gamma_{P \Theta}+\gamma_{\Theta \Delta}\right) g\left(\tau, a_{\Theta}\right) \\
& -\frac{2}{a_{\Delta}}\left(\gamma_{\Delta \Delta}-\gamma_{P \Delta}+\gamma_{\Theta \Delta}\right) g\left(\tau, a_{\Delta}\right)+\frac{\gamma_{\Theta \Theta}}{2 a_{\Theta}} g\left(\tau, 2 a_{\Theta}\right) \\
& +\frac{\gamma_{\Delta \Delta}}{2 a_{\Delta}} g\left(\tau, 2 a_{\Delta}\right)+\frac{\gamma_{\Theta \Delta}}{a_{\Theta}+a_{\Delta}} g\left(\tau, a_{\Theta}+a_{\Delta}\right) .
\end{aligned}
$$

Furthermore,

$$
\begin{aligned}
\operatorname{Var}[Q(t+\tau)-Q(t)]= & \operatorname{Var}\left[Q(t+\tau)-Q(t) \mid \mathscr{F}^{i}(t)\right]+\frac{\gamma_{\Theta \Theta}}{2 a_{\Theta}}\left[g\left(\tau, a_{\Theta}\right)\right]^{2}+\frac{\gamma_{\Delta \Delta}}{2 a_{\Delta}}\left[g\left(\tau, a_{\Delta}\right)\right]^{2} \\
& +\frac{\gamma_{\Theta \Delta}}{a_{\Theta}+a_{\Delta}} g\left(\tau, a_{\Theta}\right) g\left(\tau, a_{\Delta}\right) .
\end{aligned}
$$

From equation (C.5), we also have

$$
\operatorname{Cov}[Q(t+\tau)-Q(t), Q(t)-Q(t-\tau)]=-\eta_{\Theta}\left[g\left(\tau, a_{\Theta}\right)\right]^{2},
$$

where

$$
\eta_{\Theta}=\frac{1}{a_{\Theta}}\left(\gamma_{P \Theta}-\frac{1}{2} \gamma_{\Theta \Theta}-\frac{a_{\Delta}}{a_{\Theta}+a_{\Delta}} \gamma_{\Theta \Delta}\right) .
$$

Given the equilibrium price, its unconditional variance is:

$$
\begin{aligned}
\operatorname{Var}[P]= & p_{D}^{* 2}\left[\frac{\sigma_{D}^{2}}{2 k}+\frac{1}{k\left(a_{\Pi}+k\right)} \frac{\sigma_{\Pi}^{2}}{2 a_{\Pi}}\right]+p_{\Pi}^{*} \frac{\sigma_{\Pi}^{2}}{2 a_{\Pi}}+p_{\Theta}^{2} \frac{\sigma_{\Theta}^{2}}{2 a_{\Theta}}+p_{\Delta}^{2} \frac{\sigma_{\Delta}^{2}}{2 a_{\Delta}} \\
& +\frac{2 p_{D}^{*} p_{\Pi}^{*}}{k+a_{\Pi}} \frac{\sigma_{\Pi}^{2}}{2 a_{\Pi}}+\frac{2 p_{D}^{*} p_{\Delta}}{k+a_{\Delta}}\left[\sigma_{D \Delta}+\frac{\sigma_{\Pi \Delta}}{a_{\Pi}+a_{\Delta}}\right]+2 p_{\Pi}^{*} p_{\Delta} \frac{\sigma_{\Pi \Delta}}{a_{\Pi}+a_{\Delta}}+2 p_{\Theta} p_{\Delta} \frac{\sigma_{\Theta \Delta}}{a_{\Theta}+a_{\Delta}}
\end{aligned}
$$

Acknowledgements. I am very grateful to Sanford Grossman for his encouragement and many suggestions. Many thanks go to Darrell Duffie, Bernard Dumas and Richard Kihlstrom for valuable comments. Helpful comments are also made by Anat Admati, Michael Brennen, John Campbell, George Constantinides, Doug Diamond, Phil Dybvig, Chi-fu Huang, Alan Kleidon, Albert Kyle, Andrew Lo, George Pennacchi, Paul Pfleiderer, Krishna Ramaswamy, Richard Roll, Stephen Ross, Qi Shen, Kenneth Singleton, Sheriden Titman and participants of workshops at Carnegie-Mellon, Chicago, Columbia, Duke, Harvard, London School of Economics, M.I.T., Michigan, Minnesota, N.Y.U., Northwestern, Ohio State, Princeton, Rochester, Stanford, Tel-Aviv, UCLA, Wharton and Yale. Paul Valentin and Jiyong Liu provided able research assistance. This paper is a revised version of Chapter 2 and 3 of my University of Pennsylvania Ph.D. dissertation and was circulated earlier under the title, "Asset Prices, Stock Returns, Price Volatility, Risk Premium, and Trading 
Strategies under Asymmetric Information." I also thank a referee for useful suggestions. Any errors are of course my own.

\section{REFERENCES}

ABEL, A. (1988), “Asset Prices under Heterogeneous Beliefs: Towards the Resolution of the Equity Premium Puzzle" (Wharton School, University of Pennsylvania, mimeo).

ANDERSON, B. D. and MOORE, J. B. (1979) Optimal Filtering (New Jersey: Prentice-Hall).

ANDREASSEN, P. and KRAUS, S. (1988), "Judgemental Prediction by Extrapolations" (Harvard University, mimeo).

ARNOLD, L. (1974) Stochastic Differential Equations: Theory and Applications (New York: John Wiley).

BARSKY, R. B., and DE LONG, J. B. (1989), "Why have stock prices fluctuated?", (mimeo).

BENSOUSSAN, A. and VAN SCHUPPEN, J. H. (1985), "Optimal Control of Partially Observable Stochastic Systems with an Exponential-of-Integral Performance Index”, SIAM Journal of Control and Optimization, 23, 599-613.

BLACK, F. (1976), "Studies of Stock Price Volatility Changes", Proceedings of the Business and Economic Statistics Section, (American Statistical Association), 177-181.

BROWN, D. P. and JENNINGS, R. H. (1989), “On Technical Analysis”, Review of Financial Studies, 2, 527-552.

CAMPBELL, J. Y. and KYLE, A. S. (1988), "Smart Money, Noise Trading and Stock Price Behaviour", Review of Economic Studies (forthcoming).

CAMPBELL, J. Y. and SHILLER, R. J. (1988), "The Dividend-Price Ratio and Expectations of Future Dividends and Discount Factors", Review of Financial Studies, 3, 195-228.

CARINO, D. R. (1987), “Multiperiod Security Markets with Diversely Informed Agents” (Stanford University, Unpublished Ph.D. Dissertation).

CASE, K. and SHILLER, R. (1988), "The Behavior of Home Buyers in Boom and Post Boom Market" (NBER Working Paper 2748).

DE LONG, J. B., SHLEIFER, A., SUMMERS, L. H. and WALDMANN, R. J. (1990), "The Economic Consequences of Noise Traders", Journal of Political Economy, 98, 703-738.

DE LONG, J. B., SHLEIFER, A., SUMMERS, L. H. and WALDMANN, R. J. (1980), "Positive Feedback Investment Strategies and Destabilizing Rational Speculation”, Journal of Finance, 45, 379-395.

DETEMPLE, J. B. (1986), "Asset Pricing in a Production Economy with Incomplete Information", Journal of Finance, 41, 383-391.

DOTHAN and FELDMAN, D. (1986), "Equilibrium Interest Rates and Multiperiod Bonds in a Partially Observable Economy”, Journal of Finance, 41, 369-382.

DUFFIE, D. and HUANG, C.-F. (1986), "Multiperiod Security Markets with Differential Information: Martingales and Resolution Times", Journal of Mathematical Economics, 15, 283-303.

EPSTEIN, L. G. and ZIN, S. E. (1989b), "Substitution, Risk Aversion, and the Temporal Behavior of Comsumption and Asset Returns: An Empirical Analysis", Journal of Political Economy (forthcoming).

FAMA, E. F. and FRENCH, K. R. (1988), "Permanent and Transitory Components of Stock Prices", Journal of Political Economy, 96, 246-273.

FLAVIN, M. A. (1983), "Excess Volatility in the Financial Markets: A Reassessment of the Empirical Evidence”, Journal of Political Economy, 91, 929-956.

FLEMING, W. H. and RISHEL, R. W. (1975) Deterministic and Stochastic Optimal Control (New York: Springer-Verlag).

FRENKEL, J. and FROOT, K. (1988), “Explaining the Demand for Dollars: International Rates of Return and the Expectations of Chartists and Fundamentalists", in R. Chambers and P. Paarlberg, (eds.), Macroeconomics, Agriculture, and Exchange Rates (Boulder, Co.: Westview).

FRENCH, K. R. and ROLL, R. (1986), "Stock Return Variances: The Arrival of Information and the Reaction of Traders", Journal of Financial Economics, 17, 5-26.

GENNOTTE, G. (1986), “Optimal Portfolio Choice Under Incomplete Information”, Journal of Finance, 41, 733-749.

GREEN, J. (1973), “Informational Efficiency and Equilibrium” (Harvard Institute of Economics Research Discussion Paper, 284).

GROSSMAN, S. J. (1976), "On the Efficiency of Competitive Stock Markets where Traders Have Diverse Information", Journal of Finance, 31, 573-585.

GROSSMAN, S. J. (1977), “The Existence of Futures Markets, Noisy Rational Expectations Equilibrium and Information Externalities", Review of Economic Studies, 44, 431-449.

GROSSMAN, S. J. (1981), "An Introduction to the Theory of Rational Expectations Under Asymmetric Information", Review of Economic Studies, 48, 541-559.

GROSSMAN, S. J. and SHILLER, R. J. (1981), "Consumption Correlatedness and Risk Measurement In Economies with Non-Traded Assets and Heterogeneous Information", Journal of Financial Economics, 10, 195-210.

HARRISON, M. and KREPS, D. (1979), “Martingales and Multiperiod Securities Markets”, Journal of Economic Theory, 20, 381-408.

HE, H. and PEARSON, N. D. (1988), "Consumption and Portfolio Policies with Incomplete Markets and Short-Sale Constraints: the Infinite Dimension Case" (Sloan School of Management, M.I.T., mimeo). 
HELLWIG, M. (1980), “On the Aggregation of Information in Competitive Markets", Journal of Economic Theory, 26, 279-312.

KLEIDON, A. W. (1986), "Variance Bounds Tests and Stock Price Valuation Models", Journal of Political Economy, 94, 953-1001.

KREPS, D. (1977), “A Note on Fulfilled Expectations Equilibria”, Journal of Economic Theory, 14, 32-43.

LEROY, S. F., and PORTER, R. D. (1981), "The present-Value Relation: Tests Based on Implied Variance Bounds", Econometrica, 49, 555-574.

LIPTSER, R. S. and SHIRYAYEV, A. N. (1977) Statistics of Random Processes I, II, (Berlin: Springer-Verlag).

LO, A. W. and MACKINLAY, A. C. (1988), "Stock Market Prices Do Not Follow Random Walks: Evidence From A Simple Specification Test", Review of Financial Studies, 1, 41-66.

LUCAS, R. E., Jr. (1972), “Asset Prices in an Exchange Economy”, Econometrica, 40, 1429-1444.

MANKIW, N. G., ROMER, D. and SHAPIRO, M. D. (1985), "An unbiased Reexamination of Stock Price Volatility", Journal of Finance, 40, 677-687.

MARSH, T. A. and MERTON, R. C. (1986), "Dividend Variability and Variance Bounds Tests for the Rationality of Stock Market Prices", American Economic Review, 76, 483-498.

MEHRA, R. and PRESCOTT, E. C. (1985), “The Equity Premium: A Puzzle”, Journal of Monetary Economics, 15, 145-161.

MERTON, R. C. (1971), “Optimum Consumption and Portfolio Rules in a Continuous Time Model”, Journal of Economic Theory, 3, 373-413.

MILGROM, P. and STOKEY, N. (1982), “Information, Trade and Common Knowledge”, Journal of Economic Theory, 26, 17-27.

NELSON, D. B. (1987), “The Time Series Behavior of Stock Market Volatility and Returns" (M.I.T., mimeo).

POTERBA, J. M. and SUMMERS, L. H. (1988), "Mean Reversion in Stock Prices: Evidence and Implications", Journal of Financial Economics, 22, 27-59.

RUBINSTEIN, M. (1974), “An Aggregation Theorem for Securities Markets”, Journal of Financial Economics, 1, 201-224.

SHILLER, R. J. (1981), “Do Stock Prices Move Too Much to be Justified by Subsequent Changes in Dividends?”, American Economic Review, 71, 421-436.

SHILLER, R. J. (1988), "Portfolio Insurance and Other Investor Fashions as Factors in the 1987 Stock Market Crash”, NBER Macro Economics Annual, 287-296.

SINGLETON, K. J. (1987), “Asset Prices in a Time-Series Model with Disparately Informed, Competitive Traders", in Barnett, W. A. and Singleton, K. J. (eds.), New Approaches to Monetary Economics (Proceedings of the Second International Symposium in Economic Theory and Econometrics) (Cambridge: Cambridge University Press).

SUNDARESAN, M. (1983), “Constant Absolute Risk Aversion Preferences and Constant Equilibrium Interest Rates”, Journal of Finance, 38, 205-212.

SUMMERS, L. H. (1986), “Does the Stock Market Rationally Reflect Fundamental Values?", Journal of Finance, 41, 591-601.

TOWNSEND, R. M. (1983), "Forecasting the Forecasts of Others", Journal of Political Economy, 91, 546-588.

WANG, J. (1990), “Intertemporal Asset Prices under Asymmetric Information” (University of Pennsylvania, Ph.D. Dissertation).

WANG, J. (1991), "A Model of Competitive Stock Trading Volume" (M.I.T. mimeo).

WEST, K. D. (1988), “Dividend Innovations and Stock Price Volatility”, Econometrica, 56, 37-61.

WHITTLE, P. (1981), “Risk-Sensitive Linear/Quadratic/Gaussian Control”, Advanced Applied Probability, 13, 764-777. 